\title{
Helgoland und die Erforschung der marinen Benthosalgen*
}

\author{
D. Mollenhauer ${ }^{1} \&$ K. Lüning ${ }^{2}$ \\ ${ }^{1}$ Forschungsinstitut Senckenberg (Frankfurt am Main), Außenstelle Lochmühle; \\ D-6465 Biebergemünd \\ ${ }^{2}$ Biologische Anstalt Helgoland, Zentrale Hamburg; Notkestraße 31, D-2000 Hamburg 52
}

\begin{abstract}
Helgoland and the history of research on marine benthic algae. Early phycological research on the island of Helgoland was performed by amateur phycologists from the adjacent coastal regions of Germany (Bremen, Hamburg, Lower Saxony and Schleswig-Holstein). These pioneers were followed by professionals, and by collectors from the mainland universities, particularly from Berlin. This second phase group includes the naturalist Christian Gottfried Ehrenberg, the zoologists Johannes Müller, Ernst Haeckel and Anton Dohrn, and the botanists Alexander Braun, Nathanael Pringsheim, and Ferdinand Cohn. The leading marine phycologist in Germany, towards the end of the 19th century, was Johannes Reinke, who finally worked at the University of Kiel. Paul Kuckuck's doctoral thesis had been supervised by Reinke who recommended him for the post of the first curator of botany at the Biological Station of Helgoland, which was founded in 1892. Kuckuck worked on the island from 1892 to 1914. After World War I, and after Kuckuck's untimely death, Wilhelm Nienburg became the second curator of botany on Helgoland, from 1921 to 1923 . The next permanent phycologist on the island, from 1925 to 1936, was Ernst Schreiber. He was followed in 1936 by Peter Kornmann, who retired in 1972 but still continues as a research worker, together with Paul-Heinz Sahling, who started to work as a technical assistant under the guidance of Ernst Schreiber in 1927.
\end{abstract}

\section{EINLEITUNG}

Europäische Politik im neunzehnten Jahrhundert, Aufblühen der Nordseebäder sowie Industrialisierung der feinmechanischen und optischen Fertigung, sie alle haben sich auch auf die Erforschungsgeschichte der Helgoländer Meeresalgen ausgewirkt. Die Kontinentalsperre Napoleons zwischen 1806 und 1813 brachte für Helgoland einen ungeahnten wirtschaftlichen Aufschwung. Die in der Deutschen Bucht vor dem Festland gelegene Insel war britische Kronkolonie und wurde zum Stapel- und Umschlagplatz für Schmuggelgut aller Art (Mohrhenn, 1928).

Nach den Befreiungskriegen verdorrte die Scheinblüte, und auf der Insel herrschte bittere Not (Samhaber, 1951; Packroß, 1952). Im Jahr 1826 gründete der unternehmungstüchtige Helgoländer Jacob Andresen S i e m en s eine Seebadeanstalt und führte den aufkeimenden Badebetrieb durch seine Beharrlichkeit zum Erfolg. Es kam dem Helgoländer Seebad wie auch den verschiedenen Vorläufern an Ost- und Nordsee zugute, daß Reisen des gehobenen Bürgertums zum Meer Mode geworden waren. Man sammelte

- Herrn Dr. Dr. h. c. Peter Kornmann zum 80. Geburtstag gewidmet. 
Naturobjekte, man malte und badete. Siemens' Vorhaben profitierte auch davon, daß die kleine Insel im deutschen Schrifttum reges Interesse gefunden hatte. Sie wird in Heinrich vo $\mathrm{K}$ Kleists journalistischen Beiträgen erwähnt, ebenso im Hause von G o e the in Weimar (Tischreden, 19. Februar 1891, nach Eckermann) und in Heinrich Heines Schilderungen seiner Nordseefahrten. So konnte Helgoland sich schließlich als Nordseebad neben seinen älteren Konkurrenten behaupten (Heiligendamm-Doberan 1793/94, Norderney 1797, Travemünde 1802, Cuxhaven 1816). Helgolandfahrten als besondere Attraktionen gab es seit 1822 von Cuxhaven, seit 1819 von Wyk auf Föhr und seit 1822 von Kiel.

\section{DIE ANFÄNGE DER ALGENFORSCHUNG: HELGOLANDFAHRTEN UND EXSIKKATENSAMMLER}

Wer als Naturfreund den Meeresstrand kennenlernt, ist von der Vielfalt und Schönheit der Flora und Fauna überrascht. Den Wunsch des interessierten Badegastes, sich eingehender darüber unterrichten zu können, erfüllte schon bald eine entsprechende populäre Literatur. In anspruchsvolleren Werken sind auch Beschreibungen und Listen der Fauna und Flora Helgolands enthalten. Zu diesen Büchern gehören die von Ernst Halli e r verfaßten "Nordseestudien" (1863a). Hallier (1831-1904) war Professor der Botanik in Jena und stand im Einflußbereich von Ernst Haeckel. Von Hallier stammt ferner "Die Vegetation auf Helgoland" (1863b) mit wertvollen Einzelbeobachtungen, etwa über Chorda filum mit dem bevorzugten Standort auf den Dünenklippen: „... Noch müssen wir des Seebindfadens, Scytosiphon Filum Ag., Erwähnung thun, den man sehr häufig an der Ostseite der Düne sieht und zu dessen Beschreibung man eigentlich nichts weiter braucht als den Namen, denn in der That ist der Thallus ein langer (oft 20 Fuß und darüber), dünner, schleimiger Faden" (Hallier, 1863b: pp. 41-42). Die "Nordseestudien" (Hallier, 1863a) enthalten auf 44 Seiten eine kommentierte Aufzählung von Helgoländer Meeresalgen, darunter auch der damals auf der Westseite häufigen und wärmeliebenden Dictyota dichotoma, die seit den 1950er Jahren bei Helgoland immer seltener gefunden wurde.

Auf Helgoland stieg die Zahl der Badegäste an, zum Beispiel im Jahr 1887 auf 11600 Kurgäste (davon 2000 "Passanten“, also Tagesgäste), wie der Badearzt Emil Li in de m a n n (1857-1923) in seinem Buch "Die Nordseeinsel Helgoland" berichtet (Lindemann, 1889: p. 115). Hierin finden sich neben topographischen und historischen Einzelheiten auch Darstellungen der Messungen des Pulsschlages vor und nach dem Gang zum Meeresstrand, wobei die Erhöhung der Zirkulation durch die Seeluft deutlich wird. Das Meer schlechthin fand auch großen Anklang in der Literatur, wie etwa Jakob Matthias Schleidens großes populäres Buch "Das Meer" (1867) zeigt. Justus Li e b i g, so berichtet Rudolf Sachtleben (1967: p. 220), hat sich als Junge in Captain Cooks Weltumseglungsberichte vertieft und war von den Riesentangen besonders angetan. Ein Titel wie Carl Chuns "Aus den Tiefen des Weltmeeres" (1903) wäre wohl schon damals zugkräftig gewesen. Die Ozeane steckten voller Geheimnisse, und die englischen Naturalisten hatten die Schönheit und das Bizarre der Meerestiere und -pflanzen entdeckt. Bald zeigte man solche "Sensationen" im Binnenland in Aquarien (London 1853, Hamburg 1864, Berlin 1867). Es war wichtig, das Interesse der Menschen im Binnenland zu wecken; man brauchte sie als Fürsprecher, um später die Meeresfor- 
schung politisch durchzusetzen und ihr Subventionen zu sichern. Besonders das alte Berliner Aquarium "Unter den Linden" gewann unter der Leitung des populären Alfred B r e h m (1829-1884; "Brehms Tierleben") den Wundern des Meeres viele Freunde.

Zu den Badegästen gesellten sich bald die Sammler, denen die prächtigen Algenbestände Helgolands ein lockendes Ziel waren. Sie versorgten die zahlreich aufblühenden Tauschvereine für herbarisierte Pflanzen mit Material von dem Felswatt, dem einzigen Felsenstrand vor den deutschen Küsten. Die Steilufer der Rügener Kreidefelsen liegen im Brackwasser und werden nur von einem kleinen Anteil der typischen nordatlantischen Meeresalgenflora besiedelt. Was damals alles an Funden zusammengekommen ist, läßt sich heute kaum feststellen. Wahrscheinlich wurde nicht sehr konsequent gesammelt. Man produzierte der Nachfrage gemäß eine "Ware", Sammlerobjekte für das Herbarium. Dabei hat wohl vorwiegend die Vorliebe der Käufer darüber entschieden, was in den Exsikkatenwerken angeboten wurde.

Aus der Biedermeierzeit (1815-1848) gibt es sichere Nachweise über die ersten Algensammler mit wissenschaftlichem Anspruch, die Helgoland aufsuchten. Es war eine Epoche, in der bei allgemeiner nationaler Enttäuschung nach den Befreiungskriegen in einer Art von Materialbesessenheit Natur und Geschichte erforscht wurden. Wiederum ist aber auch an den wirtschaftlichen Aufschwung zu erinnern, der vielen Naturliebhabern erst in ausreichendem Maß Geld und Freizeit für ihre naturkundlichen Liebhabereien verschaffte. Nicht wenige der forschenden Dilettanten entwickelten sich zu weltbekannten Spezialisten. Der Advokat und Bürgermeister von Jever, Georg Heinrich Bernhard J ür g e n s (1771-1846), war einer der ersten. Er war mehrfach auf Helgoland und sammelte dort die Algen für die Exsikkata in den "Decaden 4, 5, 12 und 16" (1817-1822) seiner bekannten "Algae aquaticae quas et in littora maris Dynastiam Jeveranam et Frisiam orientalem alluentis rejectas et in harum terrarum aquis habitantes". Jürgens begründete damit eine ostfriesische Naturkundlertradition, die lange angehalten hat. Ein späterer Nachfahre der ostfriesischen Heimatforschergenerationen war Rudolf R a s s a u (1839-1930) aus Aurich, der noch 1904 seine Exsikkatensammlung "Die Algen der Deutschen Nordsee-Inseln" herausgebracht hat (vgl. Peter, 1910: p. 3). Er gehörte zum Kreis der Geobotaniker um Dr. h. c. Otto L e e ge (1862-1951).

Jürgens korrespondierte auch mit Friedrich Traugott $\mathrm{Kützing}$ in Nordhausen (1807-1893), der ihn 1839 besucht hat und bei dieser Gelegenheit auch von dem neuen Seebad Cuxhaven aus nach Helgoland gefahren ist. Auf der Insel hat Kützing den Hamburger Botaniker Johann Christian Le h mann (1792-1860) getroffen (vgl. Kies, 1987: p. 235), dem er die Bekanntschaft mit Senator Nikolaus B in de r (1785-1865) verdankte. Dessen riesiges, allerdings zum größten Teil nicht selbst gesammeltes Algenherbarium hat Kützing durchgesehen (Kies, 1987: p. 234 f.).

Über Helgoland berichtet Kützing in seiner erst 1960 gedruckten Autobiographie (Kützing, 1960: p. 238): „Hier fand ich endlich, was ich suchte. Die großen Laminarien und Fucoideen, wie auch eine Menge der sogenannten Florideen wuchsen reichlich an der Felseninsel, und ich war die letzten 8 Tage meiner Ferien früh bis spät beschäftigt, diese Algen zu trocknen, zu präparieren und zu untersuchen."

Acht Jahre vor Kützings Besuch hatte der damalige Apotheker auf der Insel, H. C. Threde, die erste Centurie seines Exsikkatenwerkes bei Hoffmann und Campe in Hamburg erscheinen lassen: "Die Algen der Nordsee und die mit denselben vorkommenden Zoophyten". Nach Recherchen, die Heering (1901: p. 246) zusammengefaßt hat, 
hat Threde seine Funde nicht selbst bestimmt. Er profitierte davon, daß damals an den Küsten von Nord- und Ostsee eine Reihe von Liebhaberforschern wirkte, die eifrig miteinander korrespondierten und auch gemeinsame Untersuchungen durchführten, zumindest gemeinschaftlich ihre Exsikkata herausgaben: Johann Nicolaus B u e k (oder B u ck, gestorben 1856; Medicinalassessor), Christian Frederick (oder Friedrich) E c k Io n (1795-1868, aus Apenrade/Aabenraa; botanischer Reisender, zeitweilig in Hamburg), Friedrich Heinrich Wilhelm Frölich (1769-1846, aus Glückstadt, Pastor in Boren/Süderbrarup), Gottfried Renatus Häcker (1789-1864, Apotheker in Lübeck), Lars $\mathrm{H}$ ansen (1788-1876, Lehrer und Kantor in verschiedenen Orten Angelns), Jens Wilken Hor ne ma n n (1770-1841, von der Insel Aerö, Mediziner und Professor der Botanik in Kopenhagen), Franz Carl Mer te n s (1764-1831, Theologe und Pädagoge in Bremen), Albrecht Wilhelm Roth (1757-1834, Arzt in Vegesack bei Bremen), Otto Wilhelm Sonder (1812-1881, Apotheker in Hamburg) und Johann Nicolaus von S u h r (1792-1847, dänischer Offizier aus Heide/Holstein, arbeitete mit Frölich und Mertens zusammen; vgl. Heering, 1901; Kies, 1987: p. 100).

In Kützings "Phycologia germanica" (1845) wird Helgoland mehrmals als Fundort angegeben (so bei den Nummern 242/2, 253, 254/3, 256/2, 256/3, 269/20, 276/1, 279/2, 283/1 und 289), wobei man außer Kützings eigenen Funden immer wieder Gewährsleuten aus dem Kreis der Obengenannten begegnet. Kützings Aufzeichnungen enthalten auch Belege, daß er die Ausbeute seiner im Jahr 1839 durchgeführten Nordseefahrt mikroskopisch ausgewertet hat (Kützing, 1844). Material von Helgoland gelangte auch in die "Algen Sachsen's resp. Mittel-Europas", die Gottlieb Ludwig Rabenhorst (1806-1881) herausbrachte. Der älteste Fund stammt von Otto Bulnheim (1820-1865). Der sächsische Florist war 1859 auf der Insel und fand an ihrer Nordspitze "an Klippen, die etwas mit Erde bedeckt waren, im Jali Sphacelaria radicans Harv.". Seine Präparate sind unter Nr. 876 ausgegeben worden.

Wahrscheinlich hat sich jeder an Kryptogamen Interessierte in der hohen Zeit der Herbarien Helgoländer Algen beschafft. Viele Sammler haben die Insel selbst besucht, die meisten dürften sich Exsikkata eingetauscht haben. Eine Inventur aller dieser Bestände ist praktisch nicht durchzuführen. Immer wieder tauchen Belege in Zusammenhängen auf, die man nicht erwartet. So ist beispielsweise 1915 nach Angaben im Zugangsbuch der Botanischen Staatssammlung in München die Reinbold-Kollektion sowie ein Satz von Kuckucks Dubletten aus dem Herbarium der Königlichen Biologischen Anstalt Helgoland übernommen worden. Die angekauften Proben enthielten auch Sammlungen des Berliner Mykologen Paul Sydow (1851-1925), die Reinbold erworben hatte. Vom Maler und Ornithologen Heinrich Gätke (1814-1897), dem Begründer der Helgoländer Vogelforschung, der im Laufe seines Lebens als Wahl-Insulaner die Insel in jeder erdenklichen Beziehung zu ergründen versuchte, sind besonders schön präparierte Exemplare in Kuckucks Helgoländer Algenherbarium enthalten (vgl. Vauk, 1977, p. 40).

\section{ENTWICKLUNG UND METHODIK: MIKROSKOPIE UND PLANKTONFANG}

„Bei jeder Untersuchung muss man nicht bloss auf die entwickelten, sondern auch vorzüglich auf die unentwickelten Formen, welche sich immer wieder vorfinden, achten ... Vom Bestimmen an Ort und Stelle, mit dem Buche in der einen und der Loupe, oder dem Mikroskope in der anderen Hand, kann nicht die Rede sein. Auf algologischen 
Excursionen muss man überhaupt immer Alles mitnehmen, was sich zeigt, weil man über das Gefundene nur nach der mikroskopischen Untersuchung genau urtheilen kann" (Kützing, 1845: pp. 14 und 12). Wer damals mikroskopische Anatomie, Protozoenforschung oder das Studium niederer Algen und Pilze betreiben wollte, mußte viel Geld für ein Mikroskop anlegen und es sich wie einen Maßanzug anfertigen lassen. Kützing selbst hatte viel Mühe aufgewendet, um aus der angesehenen feinmechanisch-optischen Werkstätte von Schieck in Berlin ein wirklich brauchbares Instrument zu erhalten (Heering, 1906: p. 64). Die Linsensysteme wurden "durch Pröbeln" ausgesucht, kein Gerät war wie das andere, ein guter Wurf gelang dem Mechaniker nicht jedesmal. Erst in der zweiten Jahrhunderthälfte wurden nach Ernst Abbes Berechnung der Linsen die Herstellungsverfahren perfektioniert, wandelten sich die Manufakturen in Fabriken um, kam ein reichhaltiges mikroskopisches Instrumentarium samt vielen Präparierhilfsmitteln auf den Markt. Dieses Rüstzeug der Forschungsarbeit wurde dann so rasch verfeinert und standardisiert, daß Eduard S t r a s b u r ger (1844-1912) in seinem berühmten "Botanischen Praktikum" (Strasburger, 1884) eine erste zusammenfassende Übersicht der Pflanzenmikroskopie bieten konnte. Die industrielle Fertigung hatte diese Apparaturen nicht nur untereinander gleichwertig und leistungsfähiger werden lassen, sie waren auch erschwinglich geworden. Damit war auch die mikroskopische Untersuchung der Algen in breiterem Rahmen möglich geworden.

Im fortschrittlichen und vorbildlichen England war man schon einige Jahrzehnte zuvor über die Stufe ausgefallener Liebhaberei des Mikroskopierens hinausgelangt. Der "Conservator des anatomischen Museums und Demonstrator der Anatomie am königl. Collegium der Ärzte Englands", Peter John Q u e k e t t (1815-1861), hatte dazu Pionierarbeit geleistet (vgl. Möbius, 1937: p. 439). Der nach ihm benannte "Quekett Microscopical Club" brachte ab 1868 eine eigene Zeitschrift heraus. Damit waren vergleichbare Entwicklungen in anderen Ländern angeregt. Von den deutschen Vereinigungen, die sich nach diesem Vorbild herausbildeten, sind die "Freie Vereinigung von Freunden der Mikroskopie" und die "Deutsche mikrologische Gesellschaft" mit ihrem Organ "Mikrokosmos" besonders hervorgetreten (vgl. Francé, 1908).

Kützings Zeitgenosse, der Berliner Naturgeschichtsprofessor Christian Gottfried Ehren berg (1795-1876), war mit seinem Mikroskop einige Jahre vor dem Naturgeschichtsprofessor aus Nordhausen auf Helgoland gewesen. Danach waren es vor allem die Zoologen, die ihre Fänge in Entdeckerhochstimmung bis in die Nächte zur Verwunderung der Fischer studierten. Der Physiologe Johannes Müller (1801-1858), angeregt durch den großen Meeresbiologen Michael S ars (1805-1869), hatte die Arbeitsmöglichkeiten im neuen Nordseebad für sich entdeckt und nutzte sie von 1845 bis 1854 (Kinne, 1980). Seine Schüler Ernst Haeckel (1834-1919) und Anton Dohrn (1840-1909) sind durch seine Begeisterung für die Meeresbiologie entflammt worden. Dieser Ausdruck trifft zumindest für den impulsiven Haeckel zu. Der Berliner Botaniker Alexander Braun (1805-1877) und Nathanael Pringsheim (1823-1894; Abb. 1) steuerten in diesen Jahren Algenarbeiten mit Helgoländer Material bei. Sie regten weitere Forscher zu Inselfahrten an, etwa Leopold Kn y (1841-1916) und Paul Wilhelm Magnus (1844-1914). Ob es wirklich Johannes Müller gewesen ist, der 1845 bei Helgoland als erster Gaze zu einem Gebilde ähnlich wie ein Schmetterlingsnetz zusammennähen ließ und damit das Wasser auf der Suche nach Larvalstadien der Echinodermen durchsiebte, mag dahinstehen. Thorson (1972: p. 43) schreibt diese Idee dem 


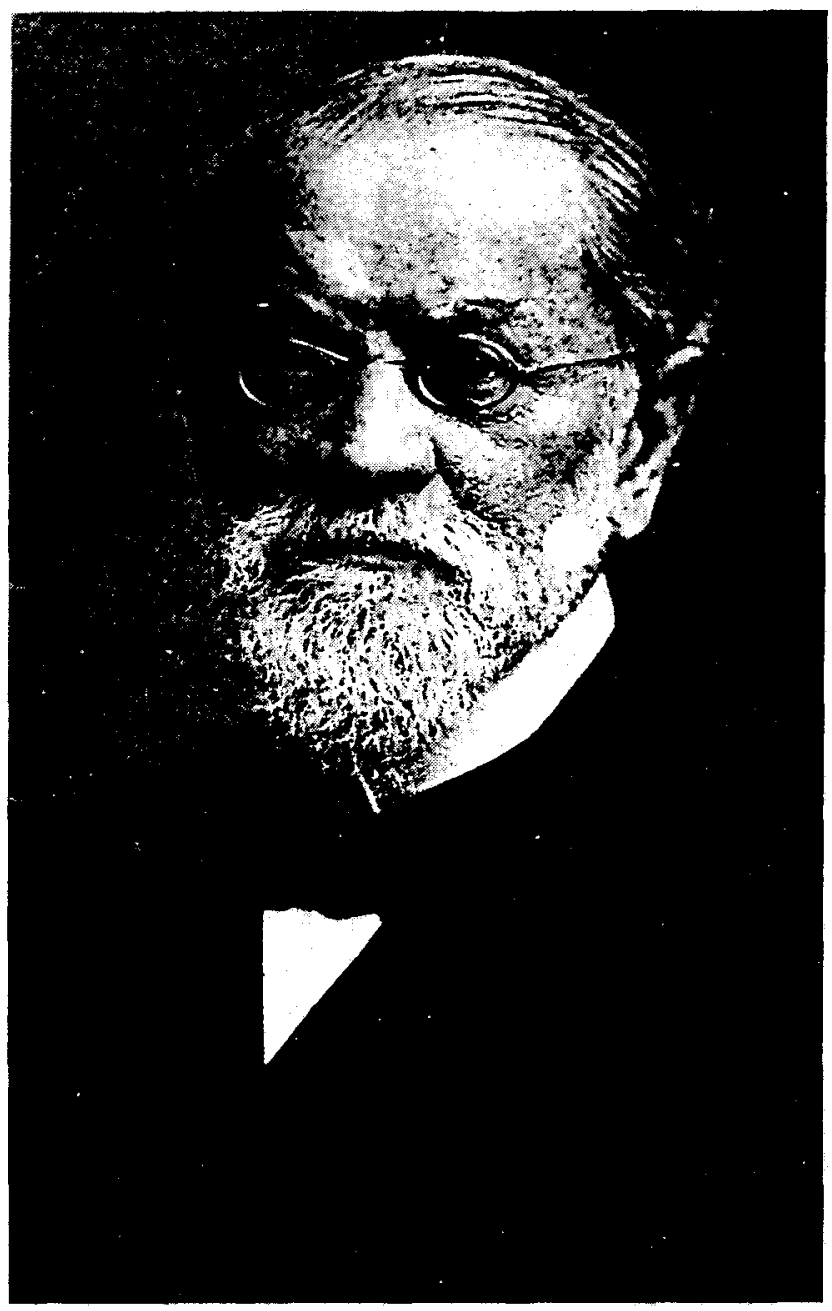

Abb. 1. Nathanael Pringsheim (1823-1894), Botaniker in Berlin, Mitinitiator der Gründung der Biologischen Anstalt Helgoland, Förderer der Algenkunde und Stifter des Nordseemuseums auf Helgoland (Photo aus. Cohn, 1901)

Engländer J. Vaughan Th o m p s o n zu. Gewiß ist jedenfalls, daß das Mikroskopieren der freischwimmenden und festsitzenden Kleinlebewesen des Meeres nun zu einem Schwerpunktthema der biologischen Forschung wurde.

Ehrenberg erkannte 1835 auf Helgoland erstmals Noctiluca miliaris als Verursacher des Meeresleuchtens. Nach diesem Erlebnis konnte er seine gelehrte Kompilation „Über das Leuchten des Meeres“ (Ehrenberg, 1834, 1835) durch eigene Beobachtungen abrunden. In Kützings 1844 erschienener Abhandlung "Die kieselschaligen Bacillarien oder Diatomeen " sind viele Aufsammlungen von Helgoland bearbeitet (z. B. Nr. 66/1 und 66/ $4,67 / 2,72 / 2$ und viele andere, bei denen die Insel nicht ausdrücklich als Fundort genannt ist). Eine folgenreiche Entdeckung gelang Alexander Braun. In seinem 
grundlegenden Werk "De algis unicellularibus nonnullis novis vel minus cognitis" (Braun, 1855) wurde Codiolum gregarium nach Material von Helgoland beschrieben, ein "Taxon", das über ein Jahrhundert später in Kornmanns Untersuchungen in den verschiedensten Zusammenhängen wiederkehrt (z. B. Kornmann, 1961b, 1973). Zehn Jahre nach Braun hat sich auch der Breslauer Botaniker Ferdinand Co h n (1828-1898; Abb. 2) mit diesem Organismus beschäftigt (Cohn, 1865). Cohn berichtete übrigens nach seinen Helgolandaufenthalten auch kurz "Über die Vegetation des Landes und des Meeres von Helgoland" (Cohn, 1862).

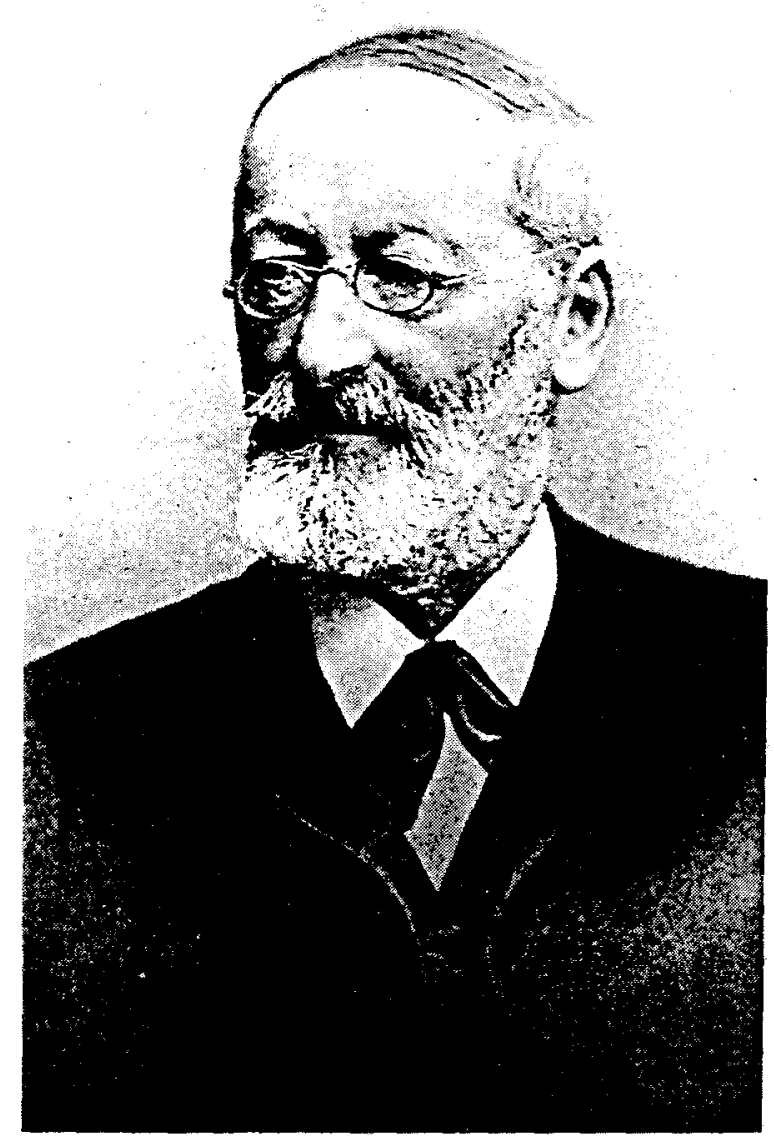

Abb. 2. Ferdinand Cohn (1828-1898) aus Breslau, der wie Nathanael Pringsheim zu den frühen Botanikern zählt, die über Algen von Helgoland publizierten (Photo aus Privatbesitz)

Ein erstes ausführliches Artenverzeichnis der Helgoländer Meeresalgen erstellte Robert Wolln y $(1881,1886)$, wobei er sich auf Kützings weitaufgliedernde Nomenklatur stützte und zum Beispiel beinahe 50 Polysiphonia- "Arten“ für Helgoland angab (heute 5 Arten; Kornmann \& Sahling, 1977) oder mehr als 10 Laminaria- „Arten “ (heute 3 Arten). 


\section{DIE KÖNIGLICHE BIOLOGISCHE ANSTALT AUF HELGOLAND}

Sachkundige Besucher haben die Algenwelt Helgolands bis in die achtziger Jahre des 19. Jahrhunderts immer wieder untersucht und geschildert. In der Fachwelt hatte man eine gute Vorstellung von der Algenflora der Nordseeinsel, wenn auch weder ein kritisch durchgearbeitetes Artenverzeichnis noch eine beschreibende Darstellung der Algenvegetation zustandegekommen waren. Aber Helgoland war zum Begriff für den Biologen im Binnenland geworden. Man durfte erwarten, daß zoologische wie phykologische Arbeiten dort erfolgversprechend waren.

Mit der Eingliederung Schleswig-Holsteins war das Königreich Preußen als führender Teilstaat des aufstrebenden Deutschen Reiches Anlieger an Nord- und Ostsee geworden, und Wilhelmshaven und Kiel wurden als Marinehäfen ausgebaut. Der Kieler Universität mit damals 500 Studenten (Reinke, 1925: p. 166) kam eine besondere Bedeutung zu. Man richtete sie deutlich auf Meeresforschung aus. Der über Hamburg nach Kiel gelangte Zoologe Karl Möbiu s (1825-1908) hatte in seiner vielbeachteten Schrift "Die Auster und die Austernwirtschaft" den Begriff „Biozönose“ geprägt (Möbius, 1877). Sein Kollege, der Ordinarius für Physiologie Viktor Hensen (1835-1924), führte anstelle des vom Sprach- und Literaturwissenschaftler Jakob Grimm vorgeschlagenen Begriffs "Auftrieb" als neues Fachwort "Plankton" ein (zunächst "Haliplankton") und gab der meeresbiologischen Forschung als Initiator der quantitativen Planktonkunde entscheidende Impulse (Hensen, 1887).

Im Jahr 1870 entstand die „Königlich-Preußische Kommission zur wissenschaftlichen Untersuchung der deutschen Meere" mit Sitz in Kiel, in der neben Gelehrten aus der Reichshauptstadt Berlin Kieler Wissenschaftler den Ton angaben (vgl. Festschrift, 1921). Ihr Publikationsorgan waren die "Wissenschaftlichen Meeresuntersuchungen". Aus deren "Abteilung. Helgoland" gingen 1937 die "Helgoländer wissenschaftlichen Meeresuntersuchungen" hervor, ab 1980 zur bibliographischen Vereinfachung in "Helgoländer Meeresuntersuchungen “ umbenannt.

Immer mehr Biologen drängten ans Meer und suchten feste Stützpunkte für die Feldarbeit. Ab 1870 war es dem initiativen Anton Dohrn (1840-1909) gelungen, in Neapel die nachmals so berühmte "Zoologische Station “ einzurichten, deren Gesamtbetrieb mit Aquarium 1874 eröffnet wurde und in deren Laboratorien seit 1873 die ersten Forscher arbeiteten (Heuss, 1940; Müller \& Groeben, 1984). Die Tagung der Deutschen Naturforscher und Ärzte 1876 in Hamburg stellte den Antrag, auf Helgoland eine zoologische Station einzurichten (Bückmann, 1959) und gründete dafür eine Kommission mit Professoren mehrerer Universitäten ( $\mathrm{rra}$ u , Ha e ckel, L e u ck a r t, Pa genstecher, Pringsheim, Sachs, H. A. Meyer). Waren schon in der Kieler Kommission angewandt-wissenschaftliche Themen angeklungen, so entstanden zur Sanierung der niederliegenden deutschen Fischerei 1870 der Deutsche Fischerei-Verein und 1885 auf der Öffentlichen Jahresversammlung, dem Deutschen Fischereitag, zur Förderung der Küsten- und Hochseefischerei die Sektion für See- und Küstenfischerei unter ihrem Gründer und Vorsitzenden Walter H e r w i g (vgl. Meyer-Waarden, 1970). Im Jahr 1888 errichtete die Sektion, Vorläuferin des 1895 juristisch eröffneten Deutschen Seefischereivereins, eine Zoologische Wanderstation in der Ems-, Weser- und Elbemündung, an der vor allem Ernst Ehrenbaum wirkte, der spätere erste Kustos für Seefischerei der Biologischen Anstalt Helgoland (Heincke, 1894: p. 2; Wohlenberg, 1953: p. 78; Mielck, 1930: p. 4). 
Als Helgoland 1890 zum Deutschen Reich kam und dem Königreich Preußen eingegliedert wurde, hatten andere europäische Staaten etwa gleichzeitig mit Anton Dohrns Gründung in Neapel oder in der Nachfolge schon ihre heute klassischen Meeresforschungsstationen eingerichtet, so die Station Biologique in Roscoff (1872), die Station in Banyuls (1881) und das Plymouth Laboratory of the Marine Biological Association of the United Kingdom (1888). Nun konnte der Funke auf Deutschland überspringen. Auch Nathanael Pring s h e i m, der Berliner Botaniker und weitblickende Initiator wichtiger Einrichtungen - er hatte 1882 die Gründung der "Deutschen Botanischen Gesellschaft" angeregt -, unterstützte gegenüber Ministerialdirektor Friedrich A l t h of f (1839-1908; Abb. 3) als Vortragendem Rat im Preußischen Kultusministerium den Plan, eine biologische Station auf Helgoland einzurichten. Althoff war der ${ }_{n}$ damals bei der Berufung von Professoren in Preußen allmächtige Mann" (Reinke, 1925: p. 16). Er hatte 1882 eine Professur in Straßburg aufgegeben, um in der Folge unter mehreren preußischen Kultusministern in Berlin zu wirken. Er war ein warmer Förderer der Idee einer staatlichen Station auf Helgoland (Heuss, 1940: p. 233; zur Biographie von Althoff vgl. Sachse, 1928).

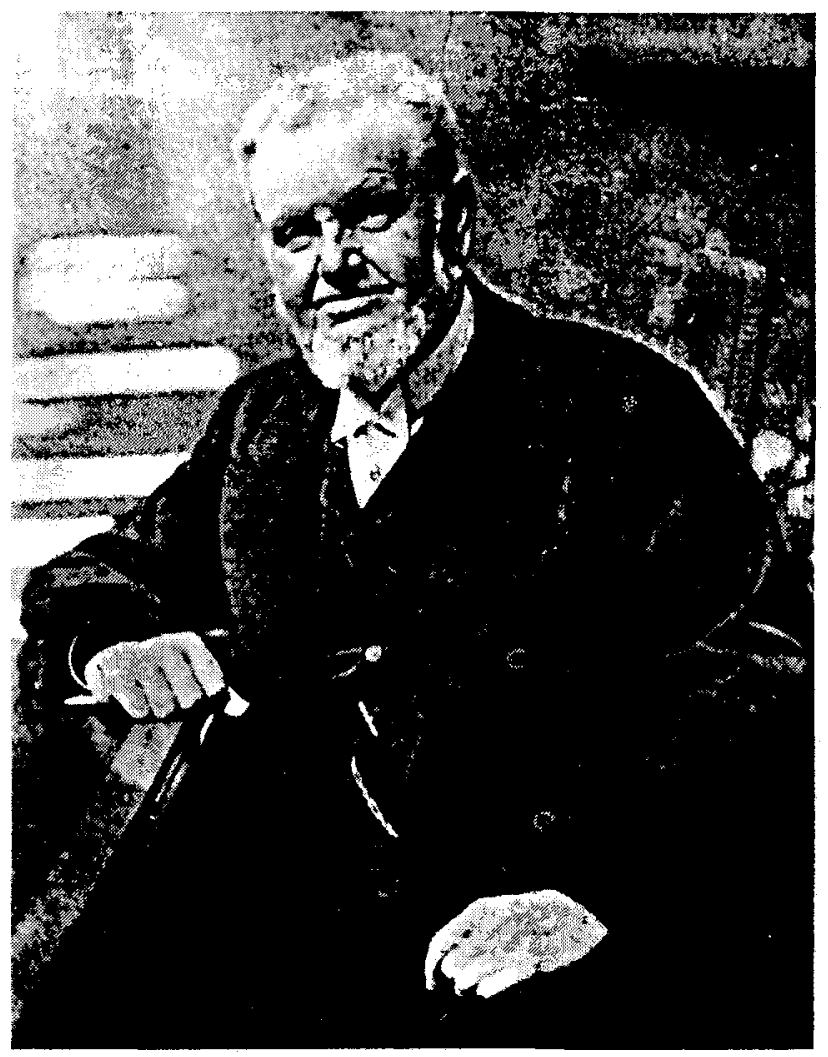

Abb. 3. Friedrich Althoff (1839-1908), Professor in Straßburg, später Ministerialdirektor im Preußischen Kultusministerium und Förderer der Idee, eine biologische Station auf Helgoland einzurichten (Photo alis Sachse, 1928) 
Später berichtet Friedrich Hein cke (1852-1929), der erste Direktor der Biologischen Anstalt Helgoland (von 1892-1921): "Der Kultusminister von Gossler wandte sofort auf Anregung des Geheimen Oberregierungsrates Althoff, dem Pringsheim mit seinem Rate zur Seite stand, der Begründung einer biologischen Station auf Helgoland seine Aufmerksamkeit zu. Er brachte den Plan, nachdem derselbe auch von der Akademie der Wissenschaften, der deutschen Zoologischen Gesellschaft und der Sektion der Hochseefischerei warm befürwortet worden war, zur Allerhöchsten Kenntnis. Se. Majestät der Kaiser und König geruhten darauf durch Cabinetsschreiben vom 31. Juli 1890 Sein großes Interesse für die Begründung einer biologischen Station für Zoologen, Botaniker und Physiologen auf Helgoland auszusprechen und Allerhöchst sich mit der weiteren Förderung des Projektes einverstanden zu erklären" (Heincke, 1894: p. 2).

Am 15. März 1892 genehmigte das Preußische Abgeordnetenhaus die Gründung der „Königlichen Biologischen Anstalt auf Helgoland“, die im April 1892 ins Leben trat und unmittelbar dem Preußischen Kultusministerium unterstellt wurde (Denkschrift, 1892; Heincke, 1918: p. 569; Hagmeier, 1952: p. 120). Für die Institution hatte Pringsheim auch noch die Bereitstellung einer botanischen Kustodenstelle erreicht. Er fand dabei Unterstützung befreundeter Berliner Kollegen wie Paul $\mathrm{M}$ a g n u s und Leopold $\mathrm{Kn}$ y, weiter auch der 1773 gegründeten "Gesellschaft Naturforschender Freunde " und des seit 1859 bestehenden und längst nicht mehr nur regional wirkenden "Botanischen Vereins der Provinz Brandenburg".

Im Jahr 1891 und auch unter der Patronage des preußischen Kultusministeriums entstand die "Zoologische Station des Berliner Aquariums" in Rovigno (heute Rovinj) an der damals zu Österreich gehörenden istrischen Küste (Schmeil, 1893; Heuss, 1940; Zavodnik, 1983), woraus sich das spätere deutsch-italienische und das heutige jugoslawische Institut für Meeresbiologie entwickelte. Die Gründung war dem sehr aktiven Pharmazeuten und Biologen Otto Hermes (1838-1910) zu verdanken, Alfred Brehms Nachfolger in der Leitung des Berliner Aquariums, der als Politiker zum engsten Kreis des einflußreichen Berufspolitikers Eugen Rich ter (1838-1906) gehörte, weswegen Anton Dohrn die finanzielle Hilfe aus Preußen für Rovigno als "Trinkgeld für Richter" bezeichnete.

Während die Gründung der Station in Rovigno von Dohrn wegen der möglichen Ablenkung des Stroms von Gastforschern und der Aussicht auf geringere preußische Subventionen für Neapel zunächst als Konkurrenz empfunden wurde, mußte die Helgoländer Station wegen der teilweisen Ausrichtung auf die Fischerei in der Nordsee ihm eher als eine Ergänzung der eigenen Bemühungen erscheinen (Heuss, 1940: p. 233). Als ab 1890 der Plan der Gründung einer Station in Helgoland im preußischen Kultusministerium diskutiert wurde, hatte der Kultusminister Gossler, der allerdings 1891 abgelöst wurde, sogar eine Zeitlang erwogen, ob man Anton Dohrn für eine Oberleitung gewinnen könne. "Das zerschlug sich. Dohrn selber meinte wohl, gesundheitlich und familiär wäre das ganz schön, aber (er hatte ja wochenlang dort gearbeitet) das Zuviel an Meer werde ihn melancholisch machen. Sein Rat ging dahin, die Anstalt mit Kiel oder Göttingen in Verbindung zu bringen, aber in dem Umfang der Anlage maßvoll zu beginnen " (Heuß, 1940: p. 233). Anton Dohrns Bedenken waren zu seinen Lebenszeiten schließlich unbegründet. Zwar gab es eine sich über Jahre hinziehende Auseinandersetzung mit Althoff, der Anstalten machte, die preußischen Zahlungen für Neapel erheblich zu kürzen, was jedoch schließlich unterblieb, und weder Rovigno noch Helgoland 
konnten in den folgenden Jahren den nicht abreißenden Strom von Gastforschern nennenswert von Neapel ablenken. Von Bedeutung war aber, "daß Rovigno ... eine praktische Spezialität pflegte, auf die Dohrn schließlich verzichtet hatte: binnenländische Aquarien mit lebendem Material zu versorgen. Außerdem wurden dort Studentenkurse eingerichtet" (Heuss, 1940; p. 234). Beides, biologischer Materialversand und Studentenkurse, wurden später auch in der Station in Helgoland zu wichtigen Funktionen.

Die Königliche Biologische Anstalt Helgoland begann ihre Forschungsarbeit nach vollendeter Einrichtung im Frühjahr 1893, worüber weiter unten zu berichten ist. Der erste Direktor Heincke betonte später: "Die Biologische Anstalt auf Helgoland ist keine bloße zoologisch-botanische Station, wie die meisten derartigen Anstalten Europas; sie hat vielmehr zugleich den Charakter eines meerwissenschaftlichen Forschungsinstituts. Gleich bei ihrer Gründung sind ihr in dieser Beziehung recht viele und große, umfassende Aufgaben allgemeiner und besonderer Art gestellt worden. Neben die allgemeine Erforschung der Nordsee nach der physikalisch-chemischen, geologischen und biologischen Seite ist hier die besondere Erforschung der nutzbaren Tiere der Nordsee gestellt, vor allem der den Gegenstand der Seefischerei bildenden Fischarten. . . Als weitere besondere Aufgabe wurde der neuen Anstalt noch die Erforschung der Geologie, der Landflora und der Landfauna der Insel Helgoland gestellt, insbesondere auch das Studium des Vogelzuges an dieser bewährten Raststätte der Wandervögel " (Heincke, 1918: p. 569). Der Arbeitsbereich der nach dem Zweiten Weltkrieg verselbständigten Vogelwarte Helgoland gehörte also ursprünglich zur Biologischen Anstalt Helgoland, die 1910 mit Hugo W eig old (1886-1973) einen etatsmäßigen ornithologischen Assistenten erhielt (vgl. Vauk, 1977: p. 48).

Es war nicht schwer, einen geeigneten jungen Wissenschaftler für die Bearbeitung der Meeresalgen auf Helgoland zu finden, denn in Kiel hatte Reinke inzwischen die Algenforschung begründet. Über ihre Entstehung wird im folgenden berichtet, wobei es immer wieder deutlich wird, wie sehr alle Glieder der Forscherkette - wie könnte es anders sein - durch Forschungsaufenthalte an den Stränden des Mittelmeeres oder auch auf Helgoland für die Lebensarbeit an Meeresalgen motiviert wurden.

\section{BERLIN UND HELGOLAND, GÖTTINGEN, NEAPEL UND KIEL: WIEGEN DER DEUTSCHEN MEERESBOTANIK}

Nathanael Pringsheim war ein vermögender Privatgelehrter. Er gab eine eigene Zeitschrift heraus ("Pringsheims Jahrbücher für wissenschaftliche Botanik") und hatte in seinem Berliner Haus Laboratorien, in denen eine ganze Reihe von Botanikern geschult wurde. Ferdinand $\mathrm{Coh} \mathbf{n}$ gehörte ebenso zu ihnen wie die Studienfreunde Johannes Rein ke (1849-1931; Abb. 4) und Paul Magn us (1844-1914), die beide als Studenten durch Nathanael Pringsheim in die Algenforschung eingeführt wurden. Pringsheim hatte 1855 bei Vaucheria das Eindringen der Spermatozoiden gesehen und gehört damit zu den Entdeckern der Befruchtung (Erstbeobachtung 1845 bei Fucus durch Decaisne und Thuret; 1848 bei Farnen durch Suminski; Nachweis der Kopulation von Ei- und Spermakern 1877 bei Tieren durch Hertwig; 1877 bei Fucus und 1884 bei Phanerogamen durch Strasburger; vgl. Möbius, 1937). Seit 1852 hatte Pringsheim auch Helgoland aufgesucht (Bückmann, 1959) und über Meeresalgen gearbeitet (z. B. Pringsheim, 1862, 


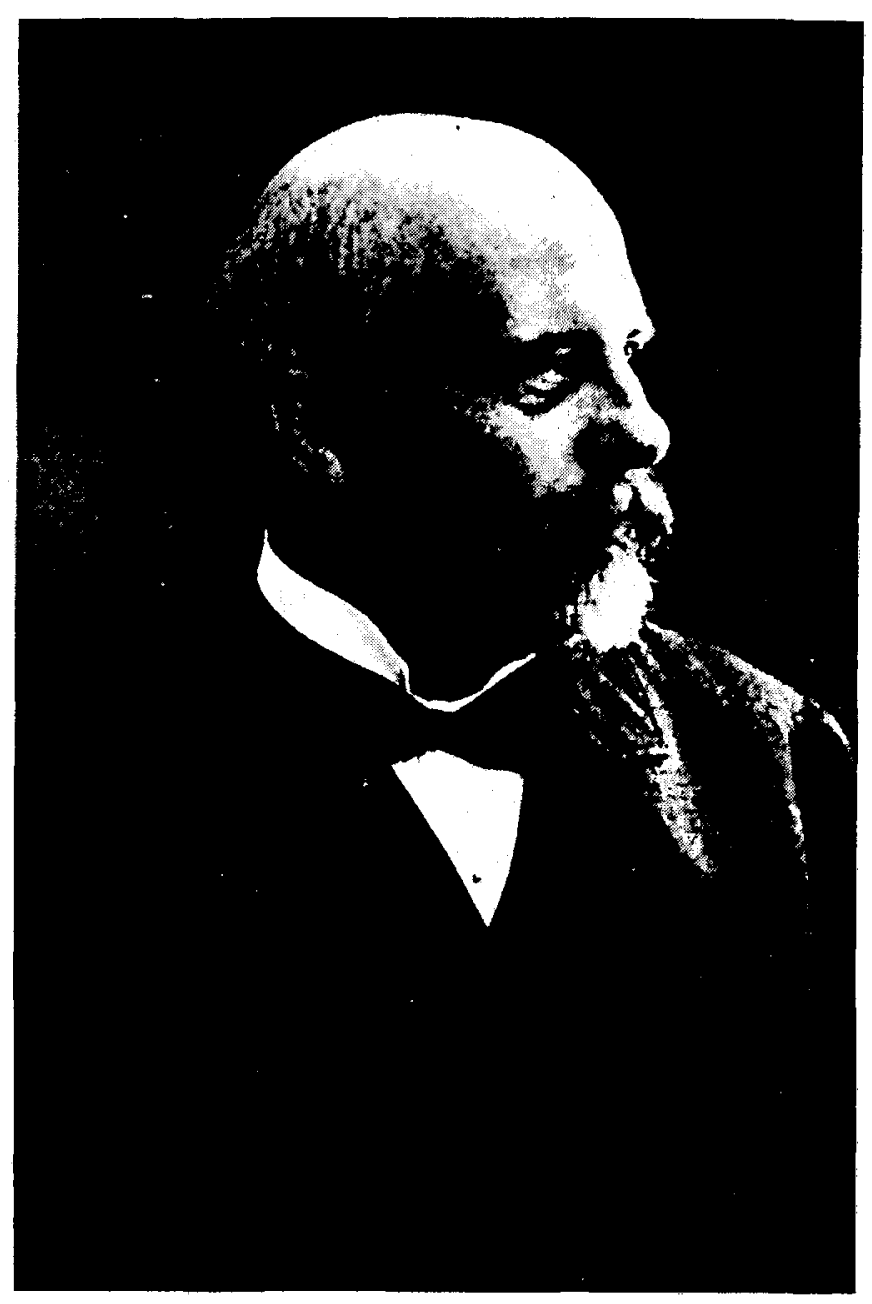

Abb. 4. Johannes Reinke (1849-1931), Pflanzenphysiologe und Algenforscher, zunächst in Göttingen, später Begründer der marinen Algenforschung an der Kieler Universität (Photo aus Reinke, 1925)

1873). Sein Schüler Reinke wurde zum "Stammvater" der später als "Meeresbotanik" bezeichneten Forschungsrichtung in Kiel, und sein Wirken ist durch eine Autobiographie gut belegt (Reinke, 1925; vgl. auch Overbeck, 1968). Im Jahr 1873, schon mit 24 Jahren, erhielt Reinke eine etatsmäßige außerordentliche Professur in Göttingen, mit der Aussicht auf den Neubau eines eigenen Instituts.

Zu den Meeresalgen als Thema seines Lebens kam Reinke endgültig im Jahr 1874 auf einer italienischen Reise mit zwei Bonner Kollegen, wobei er in Neapel die zoologische Station besuchte. "Ich sagte mir damals, als ich die Felsen von Santa Lucia mit Meeresalgen bewachsen sah, daß ein Botaniker in der Station nicht weniger erfolgreich werde arbeiten können als ein Zoologe ... Weil ich bereits in Göttingen mich im letzten 
Jahre mit Anatomie von Seetangen beschäftigt hatte, reifte schnell der Plan, einen Winter hindurch in der zoologischen Station zu arbeiten. Ich war der erste Botaniker, dem dies wichtige Institut für seine Wissenschaft sich öffnete" (Reinke, 1925: pp. 137-138). Der Gastforscheraufenthalt vom Winter 1875/76 wurde durch entwicklungsgeschichtliche Arbeiten über Dictyotaceen und Cutleriaceen (1878a, 1878b) gekrönt, die Reinke sofort als Algenforscher bekannt machten (Nienburg, 1933).

In einem Bericht an den preußischen Kultusminister Falk berichtet Reinke, "daß seine kühnsten Hoffnungen übertroffen seien: ,die ganzen Untersuchungen wurden aber nur möglich durch die in ihrer Art großartigen und in jeder Hinsicht vorzüglichen Einrichtungen der Zoologischen Station, und ich bin glücklich, durch die von mir ergriffene Initiative dieses Institut für die Botanik gewonnen zu haben'. Solche Urteile lasen Dohrns Helfer im Ministerium wie Goeppert gerne. Reinkes Besuch wurde denn auch von grundsätzlicher Bedeutung; unter die Assistenten trat ein Botaniker, die Meeresflora kam in den Bereich der Untersuchungen und späterer Publikationen. Als ein Taucherapparat in den Dienst der Forschung gestellt wurde, galt das wesentlich für die Bedürfnisse der botanischen Disziplin" (Heuss, 1940: p. 148).

Durch Reinkes Initiative gegenüber Anton Dohrn, "er möge neben dem zoologischen auch einen botanischen Assistenten an der Station anstellen" (Reinke, 1925: p. 144 f.), kam Reinkes Göttinger Schüler, der spätere Rotalgenforscher Paul F a l k e n b e r g (1848-1925), für zwei Jahre nach Neapel. Hier entdeckte er, nach Reinkes Vorarbeiten, den Generationswechsel zwischen Cutleria und Aglaozonia (Falkenberg, 1879) und steht daher mit Reinke am Beginn einer langen Reihe entwicklungsgeschichtlich forschender Phykologen. Diese führte auf Helgoland, wie weiter unten zu berichten sein wird, von Kuckuck zu Schreiber und Kornmann. In Frankreich zeichnete sich vor allem Camille S a u va ge a u (1861-1936) auf dem Gebiet der Entwicklungsgeschichte der Algen aus. Das Interesse der Botaniker an diesem Arbeitsgebiet war durch die Fülle entwicklungsgeschichtlicher Entdeckungen an Braun- und Rotalgen vor allem durch Gustave Adolphe Thu ret (1817-1875) geweckt worden (vgl. Müller, 1976), der sich zunächst in Cherbourg, später in seiner Villa auf Cap Antibes bei Nizza ein Privatlaboratorium eingerichtet hatte und durch seinen Mitarbeiter Edouard Bornet (1838-1911) unterstützt wurde. In Italien ist in diesem Zusammenhang etwa Giuseppe Meneghini (1811-1889) zu nennen, in Schweden J. G. A g a r d h (1813-1901).

Nach Falkenbergs Rückkehr nach Göttingen und Anton Dohrns Anfrage wegen eines Nachfolgers auf der botanischen Assistentenstelle an der Zoologischen Station empfahl Reinke wieder einen seiner Göttinger Schüler, Gottfried Berthold (1854-1937). Diesem gab er als Anregung mit, sich mit den Fortpflanzungsverhältnissen bei Bangia und Scytosiphon zu beschäftigen. Berthold bearbeitete die Bangiaceen (1882a) und weitete die Thematik während seines zweijährigen Forschungsaufenthaltes auf die Erforschung der Algenvegetation des Golfs von Neapel aus, auch unter ökophysiologischen Gesichtspunkten (Berthold, 1882b).

Berthold gehört zu den Vätern der vegetationskundlich orientierten Meeresbotanik, und vor ihm ist in dieser Hinsicht einer der Begründer der Pflanzensoziologie zu nennen, Joseph Romuald Lorenz (1863; wahrscheinlich Gymnasiallehrer in Salzburg; vgl. Möbius, 1937: p. 375), der über die Vegetation der Salzburger Moore arbeitete und auch über die Gesellschaften der Meeresalgen in der Nordadria: Vierzehn Jahre, bevor Möbius (1877) den Begriff "Biozönose“ schuf, unterschied Lorenz (1863) die von den 
betreffenden Algen dominierten Gesellschaften bereits als „Ulvetum" oder "LitoralCystosiretum". Im Golf von Neapel erarbeitete später Falkenberg (1878) eine ausführliche Übersicht der dort wachsenden Algenvegetation, und später setzte Funk $(1927,1955)$ diese Richtung fort.

Als im Jahr 1885 die botanische Professur in Kiel vakant wurde, machte Pringsheim die Fakultät auf Reinke aufmerksam und wies darauf hin, „daß Kiel die einzige am Meere gelegene deutsche Hochschule sei, daß deswegen ein Botaniker dorthin gehöre, der ein Interesse für Meeresalgen habe" (Reinke, 1925: p. 165). Reinke motivierte seinen Entschluß, das Kieler Ordinariat anzunehmen, mit der entscheidenden Erwägung, "daß die Algenflora der Ostsee nahezu unerforscht war, während meine Liebe zu diesen Pflanzen die alte geblieben war und durch den langen Verzicht auf die Beschäftigung mit ihnen sich zur Sehnsucht gesteigert hatte... Dann bestand in Kiel eine vom Landwirtschaftsministerium ressortierende ,Kommission zur wissenschaftlichen Untersuchung der deutschen Meere im Interesse der Fischerei', in der eine botanische Stelle vorgesehen war, die ich vermutlich im Nebenamt erhalten würde..." (Reinke, 1925: p. 170). Hier ist anzumerken, daß die Ostseealgen durchaus intensiv bearbeitet wurden, etwa in Schweden durch die Pioniere der Algentaxonomie Carl Adolph Agardh (1785-1859) und seinen Sohn Jacob Georg A gardh (1813-1901). Jedoch stand eine systematische Aufnahme der Meeresalgen, wie sie Reinke vorschwebte, noch aus. Sein schwedischer Zeitgenosse Franz Reinhold K jell m a n (1846-1907), Professor der Botanik in Uppsala und bekannter Teilnehmer an Polarexpditionen, darunter der Erstbefahrung der Nordostpassage 1878-79 mit der "Vega" unter Nordenskjöld, hatte sich mit der Algenflora im Skagerrak beschäftigt (Kjellman, 1878), sich dann jedoch der Algenflora der arktischen Küsten zugewandt (Kjellman, 1883).

Seinen Göttinger Assistenten Franz Schütt (1859-1921), einen vorzüglichen Zeichner, nahm Reinke mit nach Kiel, und Berthold wurde Reinkes Nachfolger auf der Göttinger Professur. Als Mitglieder der Kommission zur wissenschaftlichen Untersuchung der deutschen Meere traf Reinke auf schon erwähnte bedeutende Meeresforscher, "den Zoologen Möbius, der die Tiere der Kieler Bucht bearbeitete, den Physiker Karsten, der Stationen längs der deutschen Küsten zur Beobachtung der physikalischen Verhältnisse des Meerwassers eingerichtet hatte und deren Ergebnisse sammelte, den Physiologen Viktor Hensen, der die Bearbeitung der Fischnahrung und die Eiablage der Fische sich angelegen sein ließ" (Reinke, 1925: p. 179).

Die Kommission regte die Untersuchung der Entwicklung von Planktonalgen an, und Reinke schlug dieses Arbeitsgebiet seinem Schüler S ch ü t $\mathrm{t}$ vor, der an Hensens deutscher Planktonexpedition durch den Atlantik (1889) teilnahm, sich zum führenden Peridineenspezialisten entwickelte und später die botanische Professur in Greifswald übernahm. Dort studierte auch Erich Leick (1882-1956), der 1930 die "Biologische Forschungsstation Hiddensee" gründete (Leick, 1930; Gessner, 1931; Steubing, 1958; Hübel, 1982), gewissermaßen ein geistiges Enkelkind der Kieler Initiative.

Reinke selbst untersuchte vom Strand her, dann mit Ruder- und Segelboot, schließlich mit Küstendampfern und Schleppnetz systematisch die Algenflora der westlichen Ostsee, eine Arbeit, die erst wieder in unserer Zeit unter betont vegetationskundlichem Gesichtspunkt von Heinz Schwenke und seinen Schülern aufgenommen wurde (Schwenke, 1964, 1969, 1974).

Auf den über Jahre hinaus durchgeführten Dampferfahrten, auch in stürmischer See 
und im Winter bei klirrender Kälte, war Reinkes stetiger Begleiter Major a. D. Re in bold (1840-1919). "Dieser Herr besuchte mich bald nach meiner Ankunft in Kiel, erzählte mir, daß er schon als aktiver Offizier sich für die Pflanzenwelt Deutschlands interessiert und ein kleines Herbar gesammelt habe" (Reinke, 1925: p. 181). Reinbold publizierte zwischen 1889 und 1893 über die Algen der Kieler Förde, zog 1894 nach Itzehoe, betreute von dort aus die Algensammlung des Herbarium Hamburgense in den Botanischen Staatsinstituten in Hamburg und wurde mit Arbeiten über die Meeresalgen u. a. des Roten Meeres, von Niederländisch-Indien sowie die Bearbeitung des Materials der deutschen Tiefsee-Expedition von 1898-1899 zum international bekannten Algentaxonomen (Kies, 1987). Reinkes Ostsee-Studien sind in der "Algenflora der westlichen Ostsee" (Reinke, 1889a) und im "Atlas Deutscher Meeresalgen" (Reinke, 1889b, 1892) zusammengefaßt.

Dredschfahrten von Reinke und Reinbold in der Deutschen Bucht führten zur Erkenntnis, daß keine Makroalgen auf dem mobilen Substrat wachsen und der Meeresgrund in dieser Hinsicht "eine pflanzenlose Wüste ist, in welcher Helgoland mit seiner reichen Algenvegetation eine üppige Oase bildet " (Reinke, 1889c: p. 368). Reinke merkt auch an, daß Helgoland weitaus artenärmer ist als die Festlandsküsten von Schottland und Norwegen, und hier scheint "ein ähnliches Verhältnis zu bestehen, wie zwischen der Landflora oceanischer Inseln und der benachbarter Kontinente" (Reinke, 1889c: p. 369).

Insgesamt 112 Arten von Helgoländer Makroalgen enthält eine Liste Reinkes (1891). Gemeinsam mit Major Reinbold hatte Reinke auf Helgoland gesammelt, dort auch Gätkes Algensammlung durchmustert. Weiter stand ihm in Kiel das Algenherbar von Wollny zur Verfügung, und schließlich war "die Kieler Algensammlung reich an älterem Algenmaterial von Helgoland" (Reinke, 1891: p. 271)." In dieser Arbeit wird schon festgestellt, daß der Riementang Himanthalia elongata auf Helgoland angetrieben wird, aber dort nicht Fuß faßt, und daß der Knotentang Ascophyllum nodosum bei Helgoland nur an erratischen Granitblöcken wächst. In Reinkes Artenliste sind neben dem Grundstock der heutigen Algenflora auch einige wärmeliebende Arten aufgeführt, die jetzt bei Helgoland fehlen, so die Rotalge Laurencia pinnatifida oder die Braunalgen Dictyota dichotoma, Sporochnus pedunculatus und Arthrocladia villosa (letztere Art aus Gätkes Herbar). Die ebenfalls genannte und heute bei Helgoland als Makrothalli fehlenden Rotalgen Helminthocladia calvadosii ( $=$ purpurea) und Scinaia forcellata züchteten Kornmann und Sahling (1980) aus Mikrothalli, die heute - 50 Jahre nach Verschwinden der Makrothalli - noch bei Helgoland wachsen und wohl auf die nächste ihnen zuträgliche Temperaturphase der Nordsee warten (Kornmann \& Sahling, 1980). Überraschend war der Befund, daß die Mikrothalli der beiden genannten Vertreter der Nemaliales Conchocelis-artig und kalkbohrend sind, was erklärt, warum sie von den Untersuchern vor Kornmann und Sahling in der Natur übersehen wurden.

\section{DER ERSTE KUSTOS FÜR BOTANIK AN DER BIOLOGISCHEN ANSTALT HELGOLAND: PAUL KUCKUCK}

Paul Magnus, Junggeselle in Berlin, gewann der Algenforschung neue Jünger, indem er in väterlicher Fürsorge finanzschwache Studenten um sich sammelte, ihnen Anregungen aus seinem reichen Erfahrungsschatz und zugleich kleine Arbeitsaufträge 
gab. In den Jahren 1887 und 1888 gehörte zu diesen akademischen "Adoptivkindern", die für ihn mikroskopierten und Abbildungen als Anschauungsmaterial für Lehrveranstaltungen zeichneten, ein junger Ostpreuße aus Petricken, Kreis Labiau, Ernst Hermann Paul Ku ck u ck (1866-1918; Abb. 5-6, 10-11). Er aquarellierte akkurat die gemeinsam mit seinem Mentor gesammelten Algen. Einige Proben dieser frühen Kunstfertigkeit sind im Herbarium Magnus erhalten, das im Institut für Allgemeine Botanik der Universität Hamburg verwahrt wird.

Wie Kuckucks Weg nach Kiel und später nach Helgoland führte, berichtet Reinke in seiner Autobiographie (Reinke, 1925: p. 185): Schütt " gab die Assistentenstelle auf, um

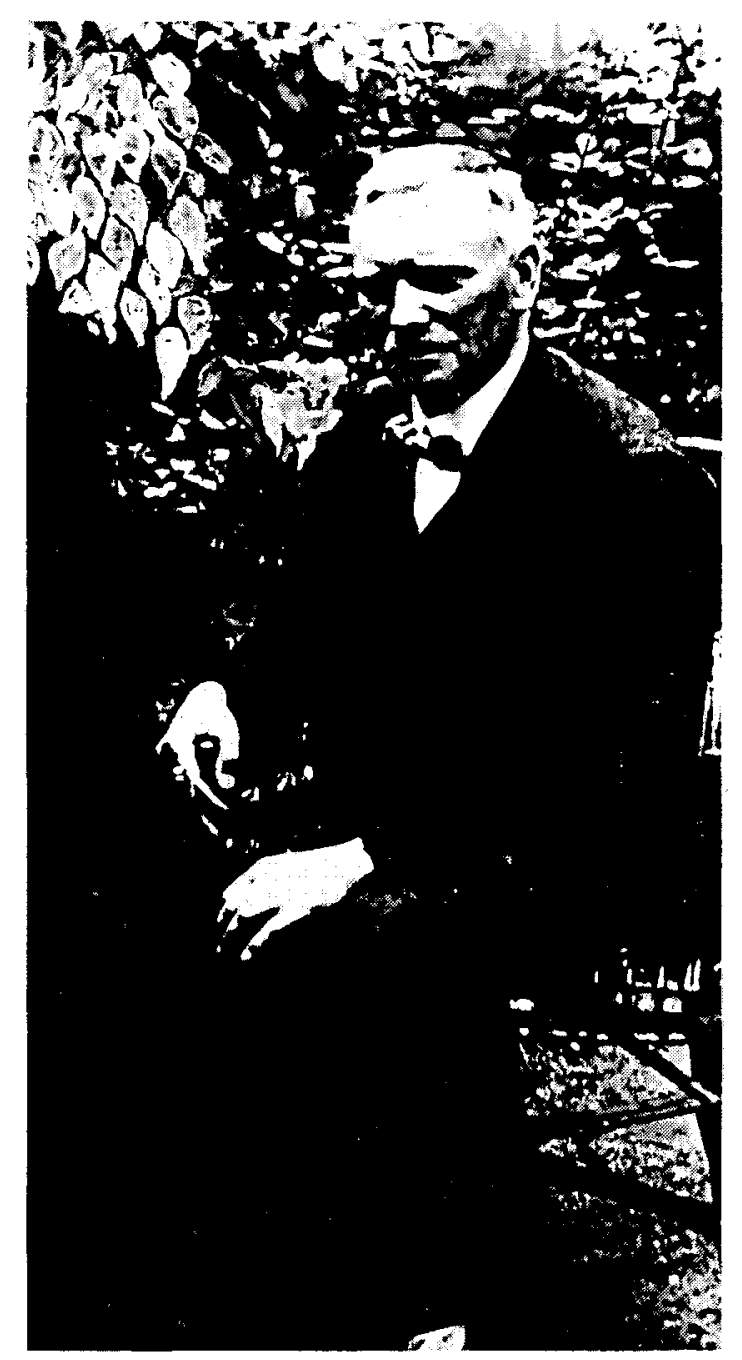

Abb. 5. Paul Kuckuck (1866-1918), der erste Kustos für Botanik an der Biologischen Anstalt Helgoland (Photo aus Privatbesitz) 
sich ganz seinen eigenen Studien hinzugeben und sich auf die Habilitation an der Kieler Universität vorzubereiten. $\mathrm{Zu}$ dem Ende ging er zunächst nach Neapel, um in der zoologischen Station die dortige Algenwelt kennenzulernen. Da mir in Kiel ein gleichgewandter Zeichner fehlte, wandte ich mich an meinen alten Studiengenossen Paul Magnus in Berlin mit der Anfrage, ob er mir unter den dortigen Studenten einen guten Zeichner als Assistenten empfehlen könne. Magnus empfahl mir den Studiosus Paul Kuckuck, den ich nach eingesandten Zeichenproben als Assistenten annahm. Kuckuck hatte sich bei seinem Eintreffen in Kiel noch gar nicht mit Algen beschäftigt; " (hier trügt Reinkes Erinnerung, wie wir gesehen haben!) "er arbeitete sich aber schnell in die Materie ein, und im Zeichnen erwies er sich Schütt ebenbürtig. Ich war damals gerade mit einer monographischen Studie über die von mir in der Ostsee aufgefundenen Tilopterideen, eine besonders interessante Algengruppe, beschäftigt, und überließ ihm zunächst die Ausführung der zu dieser Arbeit gehörenden Tafeln; die Abhandlung ist in der Botanischen Zeitung veröffentlicht. Danach übertrug ich ihm die Herstellung der zu Heft I des Atlas noch fehlenden Abbildungen; die Tafeln des Heft II hat Kuckuck allein gezeichnet. Weil ich in Gemeinschaft mit Kuckuck eine Durcharbeitung des von mir für das Kieler Botanische Institut zusammengebrachten großen Algenherbars vornahm, war Kuckuck auf das gründlichste in die Algenkunde eingeführt worden, so daß ich ihn zum Botaniker für die auf Helgoland unter Heinckes Leitung gegründeten Biologischen Anstalt empfehlen konnte; dieser Anstalt überließ ich fortan auch die weitere Erforschung der Helgoländer Algenflora. Kuckuck hat sich auf Helgoland vortrefflich bewährt und eine Reihe ausgezeichneter algologischer Arbeiten geliefert, während des Krieges wurde er der Wissenschaft durch einen allzu frühen Tod entrissen."

Kuckuck promovierte im Sommer 1892 über Ectocarpus-Arten der Kieler Förde, und damit war die Thematik vorgegeben, die zum Kernpunkt seines Lebenswerks wurde, nämlich Systematik, Morphologie und Fortpflanzung der Braunalgen. Die Arbeit am lebenden Material war für Reinke und seine Schüler, neben der Wertschätzung von Herbarmaterial, wichtig. „Die Meeresalgen der europäischen Küsten sind immer noch vergleichbar einem Baume voll reifer Früchte, nach denen man nur die Hand auszustrekken braucht... Ist dann, wie durch das botanische Institut in Kiel, die Möglichkeit gegeben, die Schätze des Meeres nicht nur in bequemer Weise zu heben, sondern auch die Pflanzen lebend zu beobachten, so ist ein wichtiger Schritt zur Überwindung der äußeren Schwierigkeiten getan, welche sich dem Studium der Meerespflanzen entgegenstellen" (Reinke, 1888: p. 14).

Auch die Laborkultur von Algen wurde begonnen. Das zeigt die Einrichtung einer "Botanischen Meeresstation" im Kieler Botanischen Institut (Reinke, 1890). Hier wurden der Öffentlichkeit in eisgekühlten Meerwasseraquarien Algen der Kieler Förde gezeigt. Für Kuckuck wurde die Beobachtung der Algenentwicklung, im Freiland wie im Labor, zur Leitschnur seiner späteren Helgoländer Tätigkeit. Denn „eigentlich systematische Studien unter Benutzung von Herbarmaterial und systematischer Literatur lagen Kukkuck ferner, auch an der Bearbeitung größerer exotischer Algensammlungen hat er sich kaum beteiligt" (Pilger, 1919: p. 65).

Kuckucks Nachfolger auf der Kieler Assistentenstelle wurde der Leipziger Privatdozent George Karste n (1863-1937), der auf Reinkes Vorschlag die benthischen Diatomeen des Meeresbodens bearbeitete. Er wurde zum anerkannten Diatomeenfachmann und ging als Ordinarius nach Halle. Zur späteren Schülergruppe von Reinke, die im 
Kieler Botanischen Institut phykologisch arbeitete, gehörten Otto Vernon $\mathrm{D}$ a r bishire, Wilhelm Benecke, Ernst Küster, Max Nordhausen, Ernst Lehman n und Richard Harder (vgl. Reinke 1925; Nienburg, 1933; Overbeck, 1968).

\section{Kuckucks Inselleben}

Auf Helgoland aber war nun ab Oktober 1892 erstmals mit Paul Kuckuck ein Phykologe ansässig und konnte über Jahre die Vegetationsentwicklung ununterbrochen beobachten (Abb. 6). Von dieser Tätigkeit geben die Publikationen sowie Kuckucks Herbartätigkeit ein eindrucksvolles Zeugnis. "Das allgemeine Herbarium umfaßt Salzund Süßwasseralgen aller Ordnungen und der ganzen Erde. Die Grundlage zu demselben bilden die 11 bisher erschienenen Faszikel der Phykotheca universalis von Hauck und Richter... Das deutsche Herbarium umfaßt nur marine Algen. Den Grundstock bildet eine Doublettensammlung von Nord- und Ostseealgen, die Herr Professor Reinke in Kiel uns gütigst aus dem dortigen Herbar überlassen hat ... Zur leichteren Orientierung der hier arbeitenden Botaniker wurde endlich das Helgoländer Herbarium angelegt... Es besteht vor allem aus den im verflossenen Winter von Dr. Kuckuck aufgelegten Pflanzen und aus den prächtigen, freilich nur der warmen Jahreszeit entstammenden Nummern des Gaetke'schen Herbariums" (Heincke, 1910: p. 140).

Außer Friedrich Heincke, dem Direktor von 1892-1921 und verdienten Erforscher der Wanderungen des Herings (vgl. Ehrenbaum, 1923), gab es zwei als Abteilungsvorstände fungierende Assistenten, Clemens $\mathrm{Hartlaub}$ für die Zoologie und Ernst Ehrenbaum für die Seefischerei. Etatmittel für die botanische Assistentenstelle waren zwar erst ab 1897 vorhanden, aber die Akademie der Wissenschaften in Berlin und das preußische Kultusministerium ermöglichten dennoch den Arbeitsbeginn auch des Botanikers noch im Gründungsjahr 1892 (Heincke, 1894: p. 21). Im April 1898 wurde Kuckuck zum Kustos und Leiter der Botanischen Abteilung der Biologischen Anstalt Helgoland ernannt. Außer den vier Wissenschaftlern bestand das Personal 1893, im ersten vollen Arbeitsjahr der Biologischen Anstalt, aus "einem Fischmeister, zwei Fischern und einem Präparator in einem einzigen Gebäude, einem allerdings sehr günstig im Unterlande an der See gelegenen Logierhause" (Heincke, 1918: p. 569).

Robert Pilge r (1876-1953), von Helgoland gebürtig, gehörte zu den Botanikern, die in Berlin die Meeresforschung förderten. Er gibt im Nekrolog Kuckuck (Pilger, 1919) ein anschauliches Bild, wie der Kustos der Biologischen Anstalt gelebt und geforscht hat. Für Kuckuck war die Insel offenbar die seinem Naturell gemäße Wirkungsstätte. Er fand hier die Kraft für ein großartiges Lebenswerk, auch wenn er zum Sammeln von Material und zur Erweiterung seines Horizontes öfter gereist ist (fünfmal nach Rovigno, vgl. Francé, 1908: p. 291; weiterhin nach Marokko, zur Kanalinsel Jersey, in die Normandie, nach England und Irland; vgl. Pilger, 1919: pp. 65-66). Im Frühjahr 1907 nahm Kuckuck auch an der Reise eines deutschen Marineschiffes in das östliche Mittelmeer teil, mit Exkursionen in Alexandria, an den Küsten von Palästina sowie der Türkei. Von Januar bis Ende April 1912 - Kuckuck war aus seiner Wohnung ausgezogen und das neue Kustodenhaus noch nicht fertiggestellt - arbeitete er als Gastforscher an der Zoologischen Station in Neapel. Bei dieser Gelegenheit knüpfte Kuckuck freundschaftliche Kontakte mit Anton Dohrn. Kuckucks Sohn, Reimer Hans Reinhard Kuckuck (geb. 1912; 


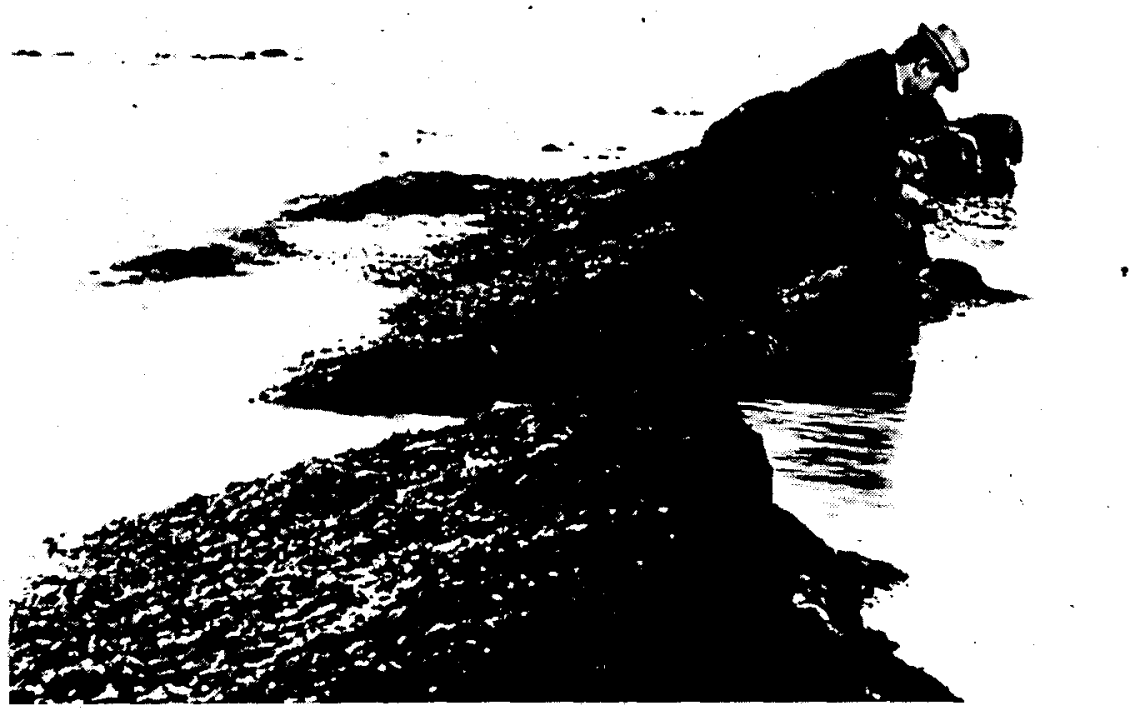

Abb. 6. Kuckuck beim Algensammeln auf den Felsklippen (Photo aus Privatbesitz)

Leiter des Christianeums in Hamburg von 1963-1977), erinnert mit einem seiner Vornamen an Anton Dohrns Sohn, Reinhard Dohrn (1880-1962).

Besonders hebt der Biograph Pilger (1919) die Bedeutung der kontinuierlichen Beobachtung der Algen am natürlichen Wuchsort hervor, ein Erfordernis jeder phykologischen Forschung, die auf das Verständnis der Lebenserscheinungen der Algen als aktive und passive Glieder der Biosphäre zielt. Allerdings fordert das Leben auf einer Insel vom Wissenschaftler und seinen Angehörigen Zugeständnisse. Viele Festländer fühlen sich auf Helgoland isoliert und fremd. Sie besuchen die Insel gern, möchten aber nicht dauernd dort leben. Manche empfinden schon die Vorstellung des Inseldaseins als bedrückend. Ernst K üste r (1874-1953), der sich schon als Reinkes Assistent in Kiel verbannt fühlte, kannte Kuckuck von Begegnungen in Rovinj. Er schrieb in seinen Memoiren (1953: p. 128) über das Jahr 1906: "Im Sommer desselben Jahres ging ich wieder einmal nach Helgoland, das ich bei leuchtendem Sommerstrandwetter zu sehen bekam und sehr genossen habe. Hier machte ich u. a. meine Beobachtungen über die Dinoflagellaten. Wie früher nahm ich auch dieses $\mathrm{Mal}$ aus Helgoland den Eindruck mit, was für große Schwierigkeiten Leben und Entwicklung derjenigen Gelehrten bedrohen, die jahraus, jahrein, nicht nur in drei oder vier liebenswürdigen Sommer-, sondern auch in acht einsamen Herbst- und Wintermonaten an dieses Eiland gebunden sind; das Schicksal von Paul Kuckuck ist mir dabei schmerzlich klargeworden - die einzigartige Vorzüglichkeit des zur Verfügung stehenden Forschungmaterials kann für ein solches Exil nicht entschädigen."

Ähnlich äußerte sich Margarethe Herte r, die Frau des Berliner Zoologen Konrad Herter (1891-1980), wenn sie in den Memoiren ihres Mannes (Herter, 1979: p. 97) einen Besuch auf Helgoland im Hause des Zoologen Helmuth Hertling (1891-1942) schil- 
dert: "Hier ist das Meer nur zur Isolation da. Es ist keine Beziehung zum Menschen, du kannst es nicht fühlen und umarmen und dich umarmen lassen, denn du bist $50 \mathrm{~m}$ steil darüber in der Verbannung und hast nur dịe kahle duftlose Fläche des Oberlandes. Unfruchtbarer Stein."

Ganz anders stellt Gottfried Vauk (1977: p. 36) die Entwicklung von Gätke auf Helgoland als Selbstfindung dar, und auch für Kuckuck brachten das Inseldasein und die "Lebensgemeinschaft" mit den Algen wohl eher einen Wissenschaftsstil mit sich, wie er den großen französischen Entomologen Jean-Henri F a b r e (1823-1915) kennzeichnet: Geduldiges, die Seinsweise der Naturdinge respektierendes Beobachten, das abwarten kann und behutsam "nachfragt“, anstatt mit gewaltsamem Experimentieren dem Studienobjekt die eigene Aktion aufzwingt.

Kuckucks rund zwei Dutzend Veröffentlichungen sind gewichtig. Er hatte immer ausführlich beobachtet, bevor er seine mit Akribie zusammengetragenen Einzeldaten zu Textbeschreibungen und vortrefflichen Abbildungen zusammenfügte. Mit seinen in Bild und Text klaren Darstellungen, vor allem niedergelegt unter den Serientiteln "Beiträge zur Kenntnis der Meeresalgen" $(1897 a, 1899,1912)$ sowie "Bemerkungen zur marinen Algenvegetation von Helgoland " $(1894,1897 \mathrm{~b})$, reiht er sich würdig neben die großen skandinavischen und französischen Meister ein. Das in der zweiten Auflage dreibändige große Algenlehrbuch von Friedrich Oltmanns (1922-1923) enthält insgesamt 797 Abbildungen. Allein 89, also mehr als $11 \%$, sind Originale von Kuckuck. Dazu kommen die aus Reinkes Publikationen stammenden Abbildungen, die Kuckuck seinerzeit als dessen Assistent gezeichnet hatte.

Der Jahresgang der Helgoländer Algenflora wurde in der Studie "Über marine Vegetationsbilder“ registriert (Kuckuck, 1897c), worin Photographien von Algen im Aquarium enthalten sind, sozusagen als Vorläufer von Unterwasserphotographien. Kukkuck verfolgte wie vor ihm Reinke und andere die Algenentwicklung auf dem Meeresgrund mit Hilfe von versenkten "botanischen Kulturkörben", und schon die Einleitung der entsprechenden Publikation zeigt den Pragmatiker: „Pringsheim erwähnt irgendwo, daß er bei seinen Helgoländer Algenstudien die im Meerwasser verankerten schwimmenden Kästen, die den Fischern zur Aufbewahrung und Fütterung der Hummern dienen, mit gutem Erfolg dazu benutzt habe, um Meeresalgen frisch zu erhalten" (Kuckuck, 1900: p. 83).

Nicht übersehen werden sollen die Arbeitsleistung an Herbarien, ebenso die Betreuung wissenschaftlicher Gäste, das Bestimmungsbuch "Der Strandwanderer" (Kuckuck, 1905) und das populäre Vademekum für den Badegast, "Der Nordseelotse" (Kuckuck, 1908). Im Nordseemuseum, einem für sich gelegenen Gebäude und von der Biologischen Anstalt betreut, befanden sich Sammlungen der Fauna, Flora und Geologie Helgolands, auch die berühmte, von Gätke zusammengebrachte Sammlung Helgoländer Wandervögel. Ein Teil der Sammlungen wurde den Helgolandbesuchern als Schausammlung gezeigt. Das Nordseemuseum, im alten Konversationshaus untergebracht, war im Jahr 1899 durch eine großzügige Spende der Erben des vermögenden Nathanael Pringsheim gestiftet worden (Henking, 1899). Seit 1902 gab es das Schauaquarium der Biologischen Anstalt, in dem auch der algenbewachsene Felsgrund gezeigt wurde (Ehrenbaum, 1910; Hagmeier, 1925).

Ab 1904 begann Kuckuck in einem botanischen Versuchsgarten von etwa $400 \mathrm{~m}^{2}$ Fläche im Oberland (Abb. 7) mit der Anpflanzung vor allem warmgemäßigter Pflanzen. 


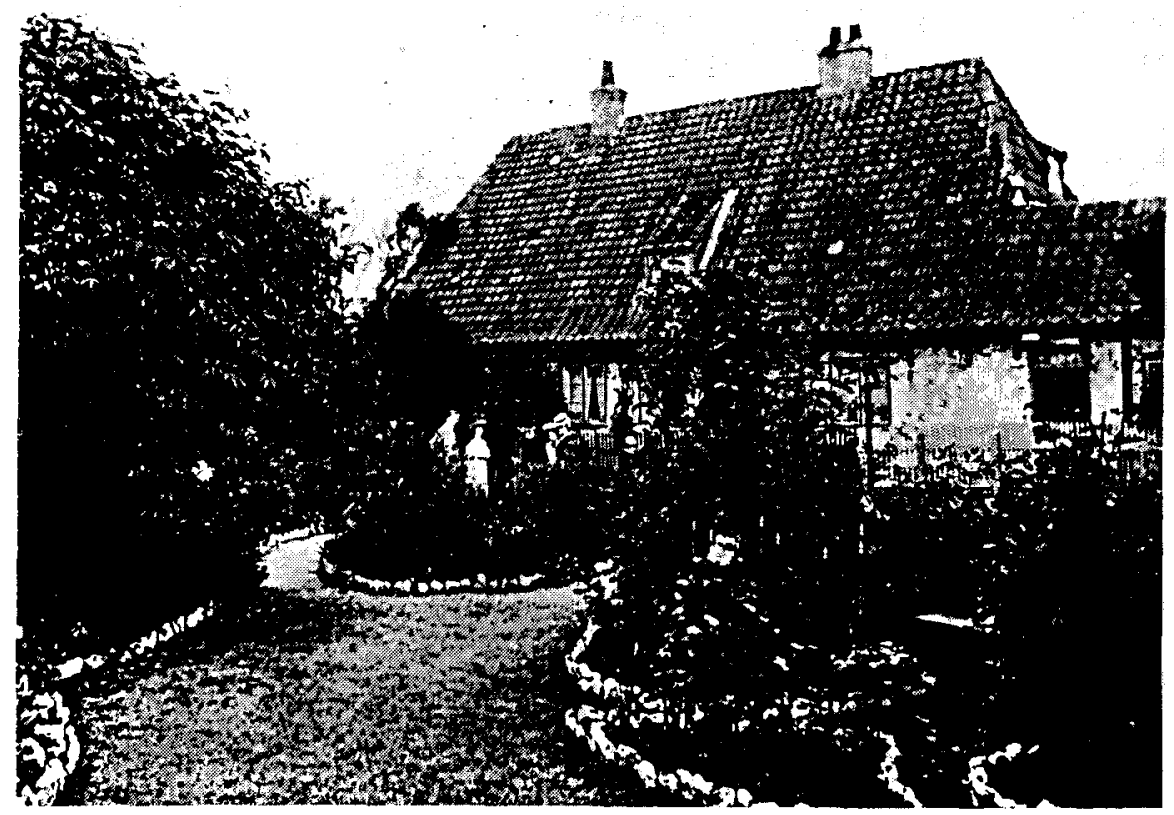

Abb. 7. Blick auf Kuckucks Versuchsgarten von Westen (Photo aus Privatbesitz)

Als Ergebnis erzielte er: "Eine ganze Reihe von Pflanzen, die auf dem Festlande entweder erfrieren oder, wenn sie durchkommen, doch gedeckt werden müssen, überwintern bei Helgoland ohne Deckung“ (Kuckuck, 1910: p. 83). Schon zuvor wuchsen bei dem milden Winterklima von Helgoland stattliche Exemplare von Feige und Maulbeerbaum, und auch der etwa 200 Jahre alte Maulbeerbaum, der die Zerstörung der Insel überlebte, hatte bereits einen Vorgänger (Kuckuck, 1910: p. 68).

Die Versuchspflanzen erhielt Kuckuck von Handelsgärtnereien und Baumschulen, aber auch von Botanischen Gärten von Dahlem, Dresden, Frankfurt a. M., Hamburg, Straßburg und aus den berühmten Rivieragärten "La Mortala" (Hanbury-Park bei Menton) sowie aus der "Villa Thuret" aus dem Cap d'Antibes, dem Besitz des Phykologen Gustave Adolphe Thuret mit einem Schatz seltener Pflanzen. Kuckucks Gartengelände setzte sich hinter dem von ihm gemieteten sogenannten "Magermannhäuschen“" am Falm zwischen der Kommandantur und Haus Redell fort (Abb. 7, 8), und zur Pachtsumme des Gartens zahlte die Biologische Anstalt einen Zuschuß. Dieses früher dem dänischen Konsul und später Jakob Magermann gehörende, inzwischen etwas baufällige Haus bewohnte Kuckuck noch einige Jahre lang mit seiner Frau. Er hatte 1909 eine Inselbesucherin geheiratet, die beim Spaziergang am Falm durch sein Klavierspiel auf ihn aufmerksam geworden war. Im Jahr 1913 zog Kuckuck, nach einem Zwischenaufenthalt im Unterland, in eines der beiden neugebauten Kustodenhäuser neben dem Leuchtturm (Abb. 9). Zuvor hatte er Pflanzen seines Versuchsgartens in die Sapskuhle umgepflanzt, weil das ursprüngliche Gartengelände bei Abriß des "Magermannhäuschens" einem großen Logierhaus für Badegäste weichen mußte. Im Jahr 1911 war die Sapskuhle als Versuchsgarten an die Biologische Anstalt Helgoland übereignet worden. Der Orni- 


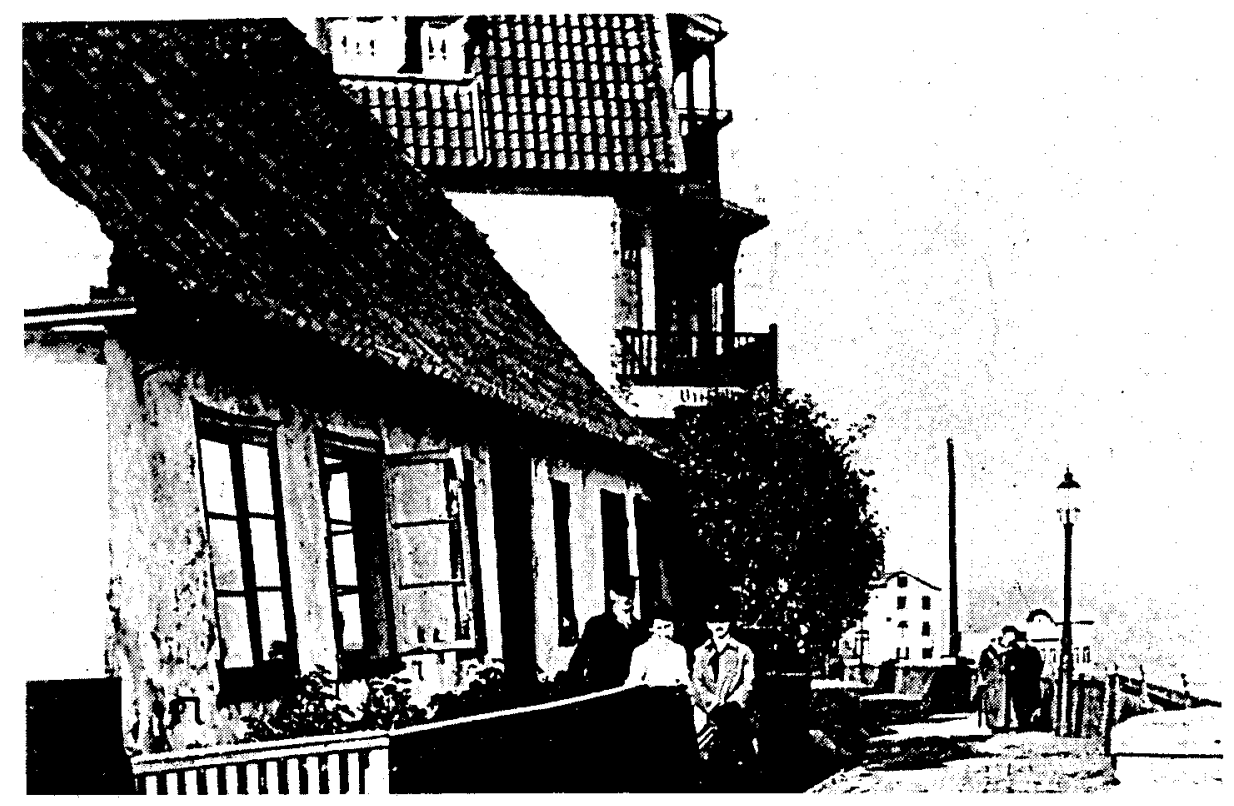

Abb. 8. Kuckucks erstes Wohnhaus, Falmseite (Photo aus Privatbesitz) Paul Kuckuck und Ehefrau Margarete (1 und 2 von links)

thologe Weigold setzte die Bepflanzung fort und legte so den ersten Fanggarten in der Sapskuhle an. Im Ersten Weltkrieg diente die Sapskuhle den Inselschafen als Pferch, wobei der mühsam gehegte Pflanzenbestand fast völlig vernichtet wurde (vgl. Vauk, 1977: pp. 52-54). Wie sehr Kuckuck es im übrigen verstand, sich auf das Wesentliche zu konzentrieren, wird aus der mündlich überlieferten Gewohnheit deutlich, zweitrangige Korrespondenz unbeantwortet in einer großen Schublade aufzuhäufen (Kornmann, nach Mitt. von Peter Krüß).

Kuckucks Helgoländer Algenherbarium hat die Inselbombardierung zu Ende des Zweiten Weltkrieges überstanden, jedoch gingen sein allgemeines Herbarium und das deutsche Herbarium verloren. Die Kisten mit Herbarmaterial waren im Keller des Institutsgebäudes eingelagert und wurden 1945/46 auf einer der drei Materialbergungsfahrten durch die britische Marine, auch dank des persönlichen Eingreifens des englischen Ozeanographen J. N. Carruthers, mit Resten der Einrichtung der Biologischen Anstalt Helgoland aus den Trümmern geborgen (vgl. Vauk, 1977: p. 73; Bückmann: 1957, p. 73). Auf diese Weise gelangte das Herbar zur Biologischen Anstalt in List und kehrte 1959 anläßlich der Wiedereröffnung nach Helgoland zurück. An der Bergungsaktion war von List/Sylt aus seitens der Biologischen Anstalt Helgoland der Aquariumsverwalter Peter Kr ü B (1884-1957) beteiligt, der 1898 als Lehrling bei Paul Kuckuck begann, ab 1922 das Aquarium verwaltete und von 1945-1952 in der Verwaltung in List tätig war. Ein anderer Veteran, Jakob Holt m an n (1887-1962), begann seine Lehre bei der Biologischen Anstalt im Jahr 1902 und wurde später Fischmeister.

Im Ersten Weltkrieg mußten die Zivilpersonen die Seefestung Helgoland verlassen. Die Wissenschaftler siedelten, soweit sie nicht zum Militärdienst eingezogen waren, mit 


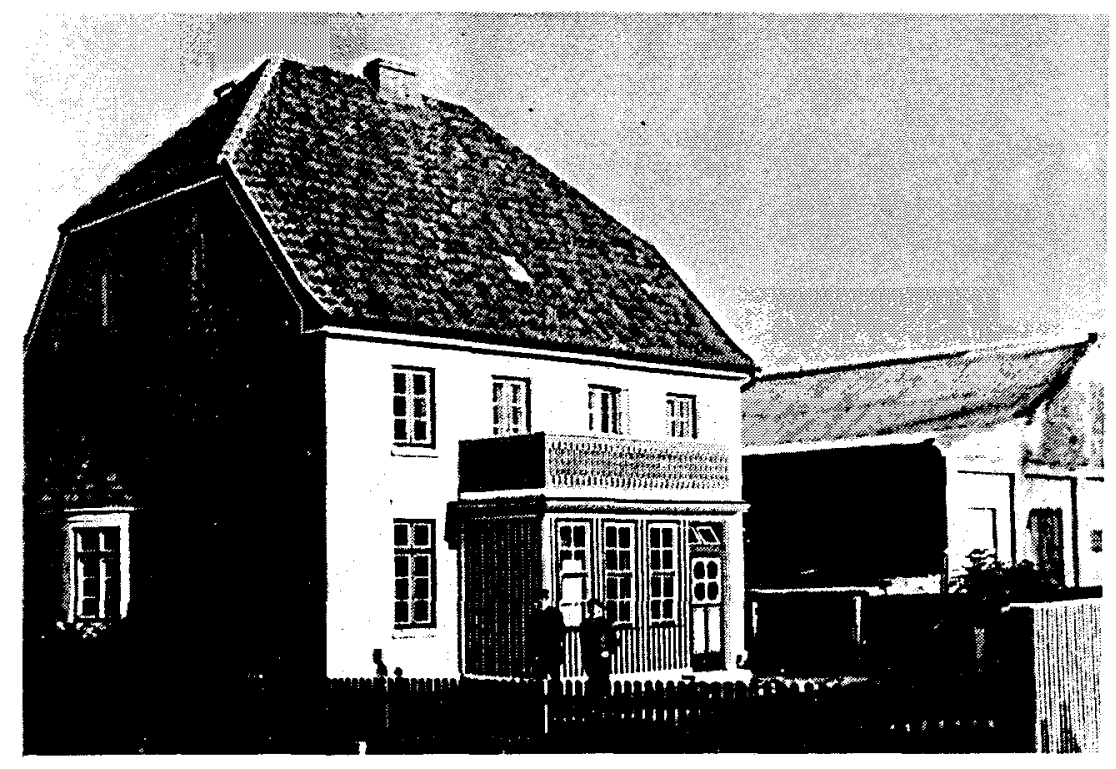

Abb. 9. Das neuerbaute, von Kuckuck im Jahr 1913 bezogene Kustodenhaus (Photo aus Privatbesitz)

der Geschäftsstelle der Biologischen Anstalt nach Oldenburg i. O. über oder nach Berlin. Das Hilfspersonal fand wie die meisten Helgoländer in Hamburg-Altona Unterkunft und arbeitete großenteils im Hamburger Zoologischen Museum weiter. Das Aquarium auf Helgoland wurde zu einem Maschinengewehr-Blockhaus umgewandelt, das Dienstfahrzeug "Augusta“ von der Marine für die Versorgung der Festung Helgoland mit Fisch requiriert, und Laminarien wurden von Marinemannschaften getrocknet und zur Herstellung von Ersatzfutter auf das Festland transportiert. Jedoch verblieben auch einige Mitarbeiter der Biologischen Anstalt im Marinedienst auf Helgoland, verbrachten wichtige Sammlungen, Archive und die Bücherei auf den ebenfalls von der Marine requirierten Reichsforschungsdampfer "Poseidon“ (Abb. 10) zur Auslagerung nach Bremerhaven (damals Geestemünde) und setzten wichtige hydrographische Untersuchungen auf $\mathrm{Hel}$ goland fort (vgl. Mielck, 1919, 1930).

Kuckuck zog 1914 mit seiner Familie nach Berlin-Lichterfelde und arbeitete in der Bibliothek des Botanischen Museums in Dahlem (heute Berlin-Dahlem). Eines der letzten Bilder zeigt Kuckuck mit seinem Freund Hans Lo h m a n n (1863-1934) anläßlich einer Besprechung in Hamburg, auf der auch die Verwendung der Meeresalgen erörtert wurde (Abb. 11). Lohmann war Zoologe in Kiel und seit 1913 Direktor des Zoologischen Museums in Hamburg. Auf den Filterapparaten der pelagischen Copelaten, feiner als die dünnmaschigste Planktongaze, hatte er Coccolithophoriden sowie Silicoflagellaten und damit das Nanoplankton entdeckt. Lohmann war der erste Ordinarius für Zoologie an der 1919 gegründeten Universität Hamburg (Remane, 1968).

Kuckuck beschreibt in seiner letzten Arbeit die Fortpflanzung von Laminaria, wobei eine in Helgoland gefertigte Zeichnung vom November 1910 die voll entwickelten, aber noch vegetativen männlichen und weiblichen Gametophyten darstellt (Kuckuck, 1917: 


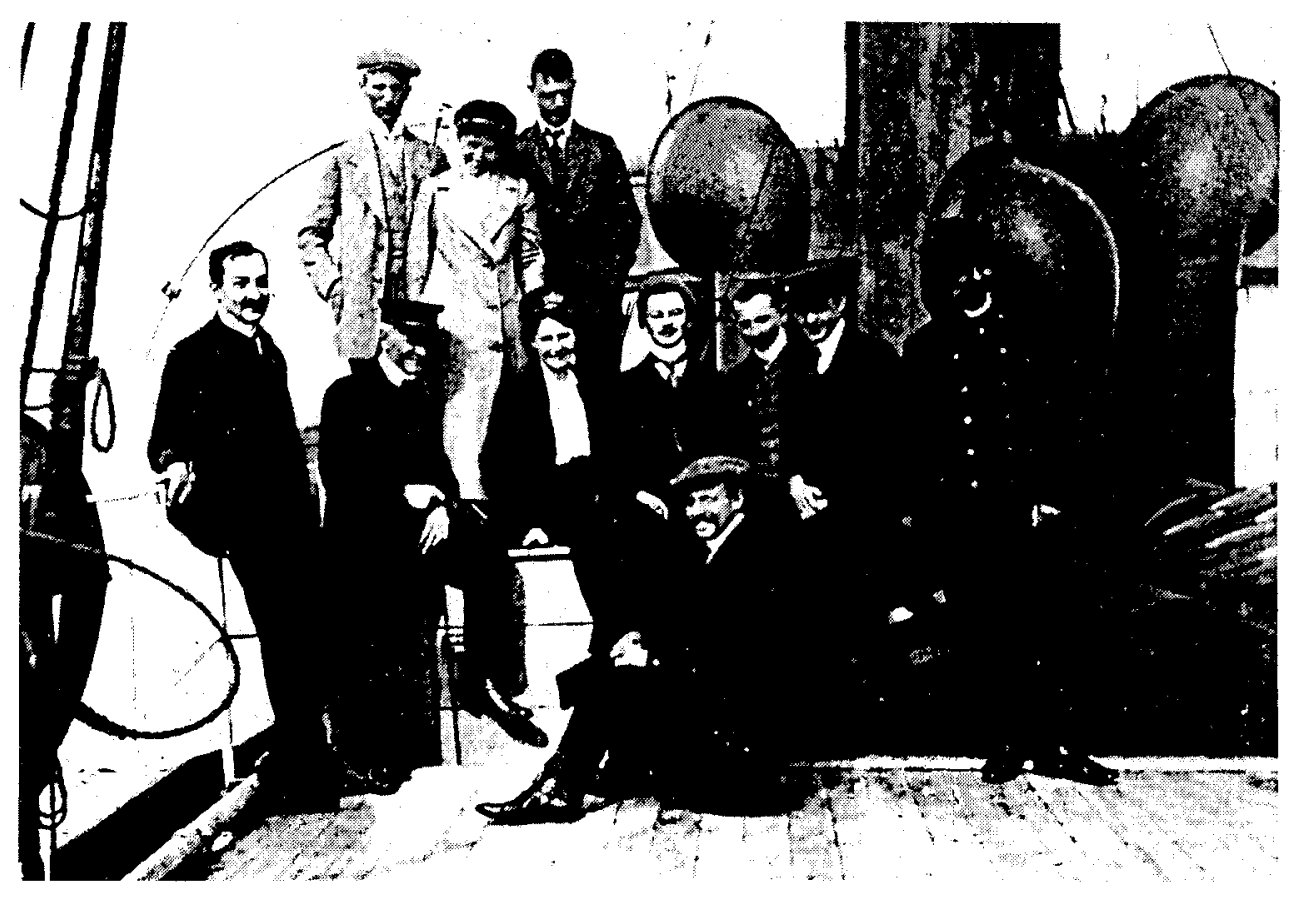

Abb. 10. Paul Kuckuck und seine Ehefrau Margarete (1. Reihe, 2. und 3. von links) auf dem Forschungsdampfer "Poseidon", der am 14. September 1911 Helgoland anlief. An diesem Tag begann eine von Dr. Hugo Weigold geleitete fischbiologische Fahrt in die Nordsee. Zu den Fahrtteilnehmern gehörten Arthur Hagmeier (1. v. li.), Dr. Thielemann, Jacob Holtmann und Dr. Wülker (Heidelberg). Weiter sind zu erkennen: Ernst Ehrenbaum (vorne, sitzend), Frau Mielck und Wilhelm Mielck (obere Reihe, 2. und 3. v. li.) (Photo aus Privatbesitz; Detailangaben von Dr. Erik Hagmeier, pers. Mitt.)

p. 567). Die Beobachtung von fertilen Gametophyten und damit die Entdeckung des Generationswechsels der Laminariales war inzwischen Sauvageau (1915) gelungen, einem Freund von Kuckuck, den er auch früher in Frankreich besucht hatte. "In günstigerer Lage wie ich, der ich bei Ausbruch des Krieges Helgoland verlassen mußte, knüpfte er an die eigentümliche Entwicklung von Saccorhiza an, um, einmal auf die merkwürdigen Zwergpflänzchen aufmerksam geworden, auch andere Laminarien in den Kreis seiner Betrachtung zu ziehen" (Kuckuck, 1917: p. 568). Ausgehend von Thallusstücken mit reifen Sori, die er sich von Helgoland nach Berlin schicken ließ, bestätigte Kuckuck mit Zeichnungen von entlassenen Eiern und entleerten Antheridien Sauvageaus Befunde.

Im Jahr 1918 ist Kuckuck, erst zweiundfünfzigjährig, an den Folgen einer Ohrenentzündung verstorben. Kuckuck hatte umfangreiche Vorarbeiten für eine "Monographie der Phaeosporeen" geleistet. "Ich werde erst wieder ein glücklicher Mensch, wenn ich diesen Berg hinter mir habe" (aus einem Brief; Kornmann, pers. Mitt.), so sah er das Ziel seiner letzten Jahre vor sich. Was von dem umfangreichen Material an Aufzeichnungen und Abbildungen des Nachlasses einer wissenschaftlichen Auswertung zugänglich zu 


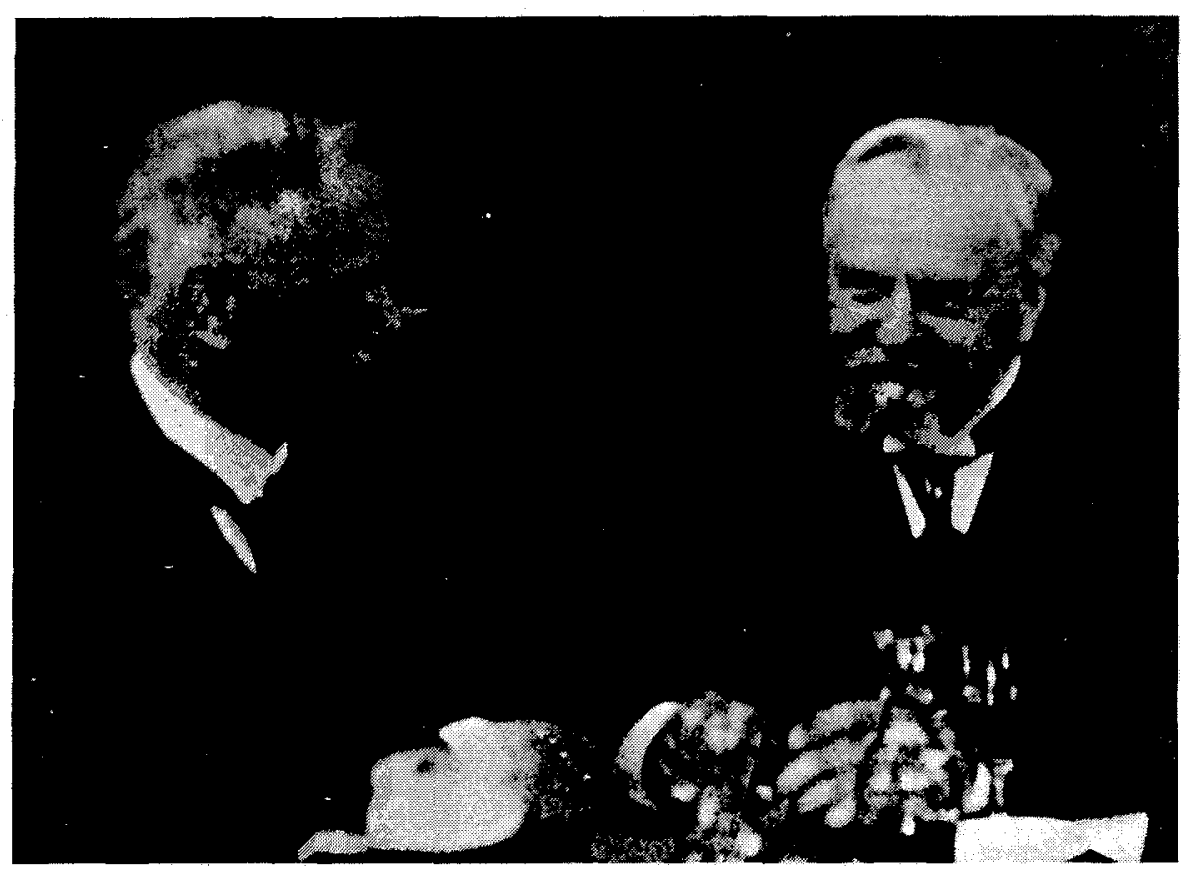

Abb. 11. Kuckuck (links), 1915 in Hamburg; gemeinsam mit Hans Lohmann, dem Entdecker des Nanoplanktons, Zoologe in Kiel; ab 1913 in Hamburg und erster Ordinarius für Zoologie der 1919 gegründeten. Universität Hamburg (Photo aus Privatbesitz)

machen war, wurde von Nienburg (Kuckuck, 1929), und in mehreren Folgen ab 1963 von Kornmann herausgegeben, unter zeichnerischer Mitarbeit von P.-H. Sahling (Kuckuck, 1964).

\section{DER ZWEITE KUSTOS FÜR BOTANIK: WILHELM NIENBURG}

Nach dem 1. Weltkrieg konnte die wissenschaftliche Arbeit an der Biologischen Anstalt nicht sogleich wieder in vollem Umfang aufgenommen werden. Von der im Versailler Vertrag vorgesehenen Zerstörung der militärischen Hafenanlagen konnte durch zähe Verhandlungen eine kleine Hafenanlage als Liegeplatz für Helgoländer Boote und das Anstaltsfahrzeug ausgespart werden, ebenso ein Marinegebäude, das der Biologischen Anstalt als Hafenlaboratorium diente (Mielck, 1930). Kurse, Gastforscher und vorübergehende Inhaber von Assistentenstellen wahrten die Kontinuität der Algenforschung auf Helgoland (vgl. Depdolla, 1920). Vor allem müssen hier der Freiburger Ordinarius Friedrich Oltman n s (1860-1945) und der Berliner Botaniker Otto Christian S ch midt (1900-1951) genannt werden. An Oltmanns' Kurse (von 1922 bis 1937) erinnern sich die wenigen noch lebenden Teilnehmer auch heute noch gerne. Die Kurse dauerten mehrere Wochen und führten auch auf die nordfriesischen Inseln (Kornmann, pers. Mitt.; Erich Oberdorfer, briefl. Mitt.).

Erst im April 1921 konnte die Kustodenstelle für Botanik mit Wilhelm Ni e n b u r g 
(1882-1932, Abb. 12) wiederbesetzt werden. Nach einer lichenologischen Dissertation hatte Oltmanns das Interesse seines Schülers auf Meeres- und Süßwasseralgen gelenkt und ihn auch im Jahr $1907 \mathrm{zu}$ einem . Gastforscheraufenthalt an der zoologischen Station in Neapel angeregt (Hoffmann, 1934: p. 232). Die Frucht dieses Aufenthaltes waren Untersuchungen zum Wachstum bei Delesseriaceen und zur Oogonentwicklung bei

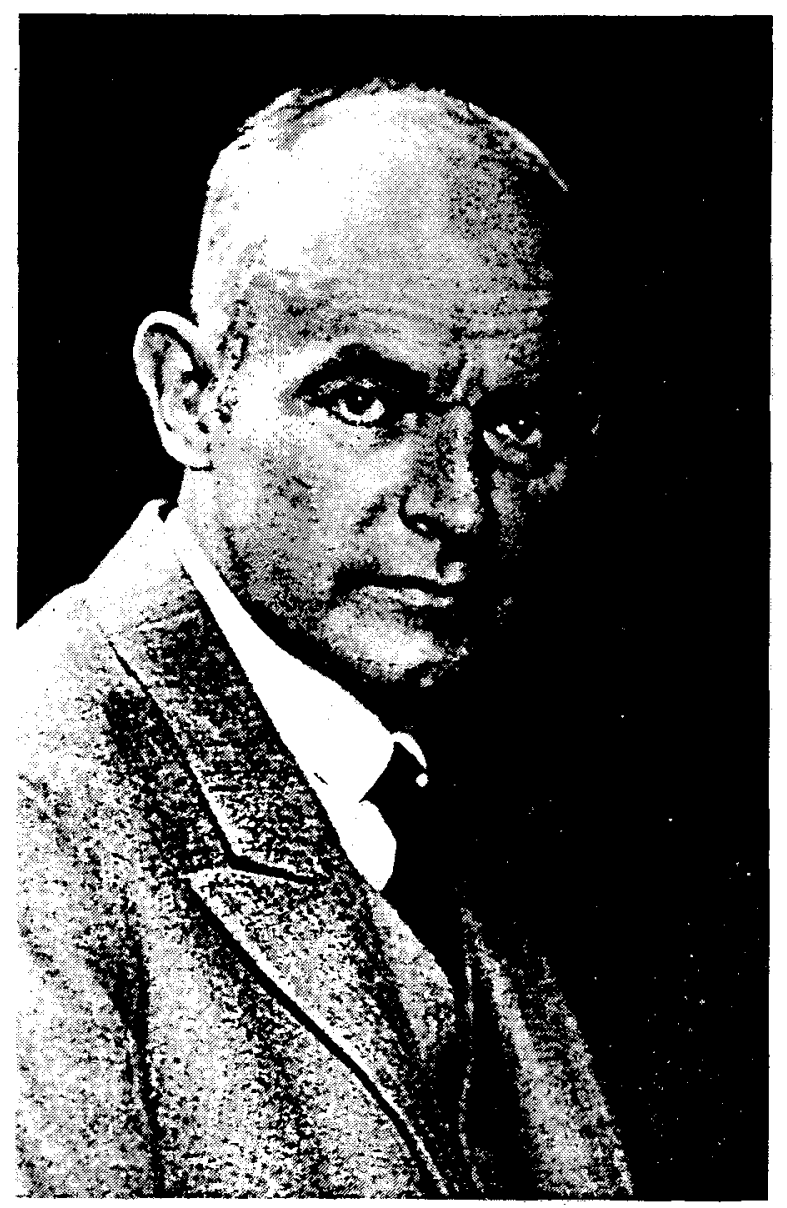

Abb. 12. Wilhelm Nienburg (1882-1932), der zweite Kustos für Botanik (Photo aus Hoffmann, 1934)

Fucaceen (Nienburg, 1908, 1910), später eine grundlegende Arbeit zur Konzeptakelentwicklung bei Fucaceen (Nienburg, 1913). Entwicklungsgeschichtliche Probleme bei Pilzen, Algen und Flechten, auch Aspekte des Geo- und Phototropismus, blieben zunächst Nienburgs Hauptinteresse. Während seiner Privatgelehrtenjahre in Berlin hatte Nienburg einen Teil von Kuckucks nachgelassenen Manuskripten für den Druck bearbeitet ("Phaeosporeen”; Kuckuck, 1929).

Nach kurzer Tätigkeit in Langenargen am Bodensee kam Nienburg 1921 nach Helgoland. Hier nahm er die noch immer ausstehende, eingehende Schilderung der 
Algenvegetation der Insel in Angriff (Nienburg, 1925). Schon früh durch ein Lungenleiden gezeichnet, verließ Nienburg aus gesundheitlichen Gründen im Frühjahr 1923 Helgoland und übernahm ein persönliches Ordinariat für Botanik in Kiel. Er konzentrierte sich in der Folge auf das Wattenmeer an der schleswigschen Westküste (Nienburg, 1927; Nienburg \& Kolumbe, 1931), wo in List auf Sylt 1924 eine Außenstelle der Biologischen Anstalt Helgoland entstanden war. Außerdem gehörte er, wie früher Reinke, der Meereskommission an. Für das "Handbuch der Seefischerei Nordeuropas". trug Nienburg einen Artikel bei über "die festsitzenden Pflanzen der nordeuropäischen Meere“ (Nienburg, 1930). Nienburg starb nur fünfzigjährig im Jahr 1932.

Sein Nachfolger wurde Curt Hof f m a n n (1898-1959), der als Schüler von Wilhelm $\mathrm{R} \mathrm{uhl}$ a nd in Leipzig um 1925 als physiologisch arbeitender Assistent zum Kieler Botaniker Georg T is c hle r (1878-1955) kam. Hoffmann wurde 1937 als Diätendozent mit der Leitung der Botanischen Abteilung des im gleichen Jahr eröffneten Instituts für Meereskunde der Universität Kiel beauftragt, wo er ab 1946 als a. o. Professor und ab 1956 als persönlicher Ordinarius für Meeresbotanik wirkte (vgl. Levring, 1959; Overbeck, 1968; Remane, 1968).

\section{LEISTUNGEN DER BESUCHER VOM FESTLAND}

Mit der Einrichtung der Biologischen Anstalt Helgoland war auch für Gastforscher die Gelegenheit zu ertragreicher Arbeit gegeben. Eine Bibliographie von 230 Arbeiten über die Algen Helgolands haben Wilhelm Nienburg und Curt Hoffmann, beide von Kiel aus, zusammengetragen (Nienburg \& Hoffmann, 1936). Diese Bibliographie lieferte auch viele Informationen für den vorliegenden Aufsatz. Otto Christian Schmidt (1900-1951) wertete nach gründlichen eigenen Untersuchungen auch die Exkursionstagebücher Kuckucks für eine Darstellung der Algenvegetation Helgolands aus, zu der dieser wegen seines frühen Todes nicht mehr gekommen war. Das fertige Manuskript ist zusammen mit Kuckucks Arbeitsunterlagen im Botanischen Museum Berlin-Dahlem ein Opfer der Luftangriffe geworden. Nur die "Vegetationsbilder" (Schmidt, 1928) und kleinere Beiträge geben noch Zeugnis von O. C. Schmidts Arbeit auf Helgoland (Schmidt, 1935, 1938), wobei die Ansiedlung der grünen "Wanderalge" Codium fragile in den frühen 30er Jahren dokumentiert wurde (Schmidt, 1935).

Wie Kützing nach enttäuschenden Strandgängen auf Wangerooge, am Schlickstrand des Jadebusens und in Cuxhaven endlich auf Helgoland die "großen Laminarien und Fucoiden" gefunden hatte, deren Tangwälder bei Ebbe rings um die Steilkante freiliegen, so erleben unzählige Studenten diesen Eindruck während der für deutsche Biologen fast obligatorischen Nordsee-Exkursionen. Viele Helgoland-Freunde unter den Dozenten der binnenländischen Hochschulen haben dieses Erlebnis immer wieder neu vermittelt. Ein besonders eindrucksvoller Lehrer ist der Botaniker, Meeresforscher und Limnologe Fritz G e s s n e r (1905-1972) gewesen, dessen letzte Wirkungsstätte das Institut für Meereskunde an der Universität Kiel war, wo er seit 1961 als Nachfolger von Curt Hoffmann die Meeresbotanische Abteilung leitete. Zuvor hatte Gessner mehrere Jahre in Venezuela gearbeitet. Durch sein Studium in Wien war ihm auch das Mittelmeer vertraut. Weiter hatte er als Assistent und Mitbegründer 1931-33 an der Biologischen Forschungsstation Hiddensee gewirkt (vgl. Hübel, 1982). "Während des dreijährigen Aufenthaltes auf Hiddensee unterhielt Gessner Kontakte zu vielen bedeutenden Gästen 
der Insel, die hier ihren Urlaub verbrachten. Namen wie Siegmund Freud, Albert Einstein, Elisabeth Büchsel und August Thienemann sind im Gästebuch zu finden. Besonders eng war die Verbindung zu Gerhart Hauptmann, mit dem er regelmäßig während der Sommermonate zusammentraf, mikroskopierte, in nächtlichen Gesprächen philosophische, politische und naturwissenschaftliche Probleme erörterte, aber auch Bacchus huldigte" (Hübel, 1982). Als Gerhart Hauptmann, der auf Hiddensee ein Haus in der Nähe der Station besaß, allerdings einen Weg zum Strand bepflanzen ließ, kam es vorübergehend zur Kontroverse mit dem "sehr rührigen Assistenten Dr. Fritz Gessner. . Er erhob schriftlich Einspruch bei Hauptmann mit der Begründung, er müsse nun, wenn er sich Wasserproben zur Untersuchung vom Strande hole, einen Umweg machen ... Hauptmann ... meinte, daß dieser junge Mann, der im nördlichen Eismeere die Höhen von Spitzbergen erstiegen habe, diesen kleinen Umweg wohl würde leisten können" (Gustavs, 1962: p. 15). Der Streitfall ging so aus, daß Hauptmann schließlich einen anderen Weg zum Strand zur Verfügung stellte. Später wirkte Gessner am Langenargener Institut für Seenforschung und Seebewirtschaftung, danach auch an der Hydrobiologischen Station Seeon/Chiemgau und kannte sich daher gut in Binnengewässern aus.

Im Sommer 1938 befaßte sich Gessner mit Nordseestudien auf Helgoland (Ohle, 1974), und dieser Insel galt eine Vorliebe des begeisterten Hochschullehrers, wie man seinen Büchern entnehmen kann. Die erste Auflage des Buches "Meer und Strand" (Gessner, 1940), ein Beitrag zu Fritz Steineckes Serie "Studienbücher Deutscher Lebensgemeinschaften" wurde großenteils im Krieg vernichtet. Sie enthält ebenso wie die zweite Auflage des weitverbreiteten Buches (Gessner, 1957) einen ausführlichen Abschnitt über Helgoland. In der zweibändigen „Hydrobotanik“ $(1955,1959)$ bezieht Gessner sich wiederum vielfach auf Forschungsergebnisse von Helgoland. Als historischer Ausblick sei vermerkt, daß Gessners Darstellungen seine Schüler nachhaltig beeinflußten. Die Tauchuntersuchungen von Klaus Lüning im Helgoländer Sublitoral (Lüning, 1970) bestimmten wesentlich auch dessen weitere Arbeitsrichtung und führten zu seinem Lehrbuch "Meeresbotanik“ (Lüning, 1985).

\section{ERNST SCHREIBER, DER DRITTE KUSTOS FÜR BOTANIK, UND P.-H. SAHLING, SEIN TECHNISCHER ASSISTENT}

Nach Nienburgs Wechsel an die Universität Kiel war die Botanikerstelle auf Helgoland wieder vakant. Oltmanns' Schüler Walter Z i m m e r m a n n (1892-1980) hatte sich nach einer Dissertation über Bodenseealgen mit Volvox befaßt und ab 1923 seine Algenstudien an der Biologischen Anstalt Helgoland fortgesetzt (Zimmermann, 1923, 1924). Er wurde später allgemein bekannt durch seine Arbeiten zur Phylogenie der Pflanzen. Der damalige Leiter der Biologischen Anstalt, Wilhelm Mi e l c k (Direktor von 1921-1933), hätte die Stelle gern mit Zimmermann besetzt. Wie einem Brief des zu dieser Zeit in Berlin-Dahlem wirkenden Hans $\mathrm{Kniep}(1881-1930) \mathrm{zu}$ entnehmen ist, war Mielck über Zimmermanns Absage recht enttäuscht (Kniep an Mielck, 21. 2. 1925; Universitätsarchiv Frankfurt am Main). Im Einverständnis mit Oltmanns empfahl Kniep einen neuen Mitarbeiter für die Inselstation, den Pharmazeuten und Botaniker Ernst S ch r e i b e r (1896-1980; Abb. 13). Dieser hatte in Bonn, Berlin und Würzburg studiert und sich durch eine vorzügliche Dissertation „Zur Kenntnis der Physiologie und Sexualität höherer Volvocales“ ausgewiesen. Kniep attestierte seinem Doktoranden: „Schreiber 


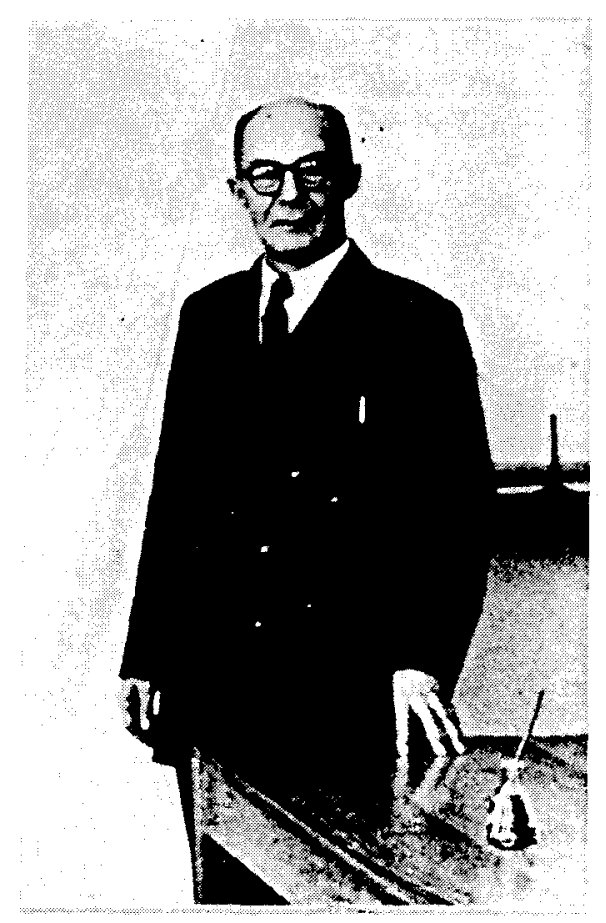

Abb. 13. Ernst Schreiber (1896-1980), der dritte Kustos für Botanik (Photo aus Privatbesitz)

ist zwar jünger, seine Vorbildung und seine Interessen sind aber vielseitiger, vor allem nach der chemisch-physikalischen Seite, worauf es Ihnen doch, soviel ich weiß, besonders viel ankommt. Er ist nicht eigentlich floristisch orientiert, sondern physiologisch, betrachtet aber die Formenkenntnis keineswegs als qualité négligeable. Sein hervorragendes Geschick im Kultivieren auch sehr schwer kultivierbarer Algen wird ihm dazu verhelfen, zahlreiche physiologische Fragen, deren Lösung von der Kultur der Algen abhängt, zu fördern" (Quelle: siehe oben).

Schreiber konnte ab 1925 die Geschäfte eines Kustos wahrnehmen, mußte aber vor seiner planmäßigen Einstellung eine größere Arbeit liefern. Er legte am 28. Juli 1927 seine Studie vor: "Die Reinkultur von marinem Phytoplankton und deren Bedeutung für die Erforschung der Produktionsfähigkeit des Meerwassers" (Schreiber, 1927). Eines ihrer Ergebnisse ist die Schreiber-Lösung, eine "auf ernährungsphysiologischer Grundlage basierende Seewassernährlösung " (Schreiber, 1927: p. 32), deren günstiges Mengenverhältnis an zugesetztem $\mathrm{NaNO}_{3}$ und $\mathrm{Na}_{2} \mathrm{HPO}_{4}$ durch Wachstumsversuche an Kulturen von Phytoplanktonalgen ermittelt wurde. Diesem für die Kultur von Meeresalgen schon recht zweckmäßigen Medium fehlten allerdings noch die Mikronährstoffe. Der Norweger Björn Föyn (1934) entwickelte Schreibers Rezept weiter und setzte Erdabkochung als Quelle für die Mikronährstoffe hinzu. „Nach einigem Experimentieren bin ich bei einer Lösung stehengeblieben, die eine Modifizierung der Schreiberschen Lösung darstellt, in der statt destilliertem Wasser Erdabkochung benutzt wird... In dieser Lösung, die "Erdschreiber' genannt wird, gedeihen die Algen ausgezeichnet." 
(Föyn, 1934: pp. 6-7). Durch Föyns Namensgebung verband sich nun der Name des dritten Kustoden für Botanik mit einem Nährmedium, wobei allerdings der Personenname im treffenden Verschmelzungsbegriff international wohl zumeist gar nicht mehr erkannt wird.

Den Werdegang der Nährlösungen für Algenreinkulturen haben zum Beispiel Bold (1942), E. G. Pringsheim (1954), von Stosch (1962) und Provasoli et al. (1957) dargestellt. E. G. Pringsheim (1881-1970), der Initiator der Algensammlung in Prag, später in Cambridge und danach in Göttingen, stammte übrigens zwar aus der weitverzweigten schlesischen Pringsheim-Familie, zu der auch Nathanael Pringsheim gehört. Die Verwandtschaft der beiden ist jedoch nur entfernt (Pirson, 1972). Ein Schüler Pringsheims aus der von 1938-1953 in Cambridge bei F. E. Fritsch verbrachten Zeit war R. Starr, der die nordamerikanische Algensammlung aufbaute.

Auch Schreibers entwicklungsgeschichtliche Untersuchungen an marinen Makroalgen führten zu grundlegenden, noch heute zitierten Befunden. Bei den Laminariales und Dictyotales wies Schreiber die genotypische Geschlechtsbestimmung nach (Schreiber, 1930, 1935). Er entdeckte die Gametophytengeneration der Desmarestiales und verfolgte die Entwicklung des jungen Sporophyten im Kulturversuch (Schreiber, 1932).

Im Jahr 1927 war der erste Teil des Hauptgebäudes der neugebauten Biologischen Anstalt vollendet worden (Hagmeier, 1934). Fast gleichzeitig mit Schreibers fester Anstellung wurde die Abteilung Botanik mit der Stelle eines technischen Mitarbeiters ausgestattet. Ein junger Helgoländer, Paul-Heinz Sa hling (Abb. 16), wurde am 1. 8. 1927 als Lehrling eingestellt. Er erfuhr eine gründliche Ausbildung unter Schreibers Leitung und wurde den Kustoden Schreiber sowie seinem Nachfolger Kornmann ein gewissenhafter Mitarbeiter. Er ist ein hervorragender Kenner der Helgoländer Algenflora und zugleich mit dem Präparieren, Kultivieren, 'Fotografieren und Zeichnen vertraut. Nach der Zerstörung der Insel nahm P.-H. Sahling von Juni 1946 bis Mai 1950 die Stationsaufgaben der Botanischen Abteilung in der nach List auf Sylt ausgelagerten Biologischen Anstalt Helgoland wahr. Er machte sich mit der Algenvegetation vertraut, legte ein Herbar sowie eine Sammlung mikroskopischer Präparate an und belieferte die Universitätsinstitute mit Kursmaterial. Im Oktober 1958 wurde Sahling nach Helgoland versetzt; die neue Meeresstation war damals noch nicht fertiggestellt. Mit einer auf Erythrocladia subintegra gegründeten neuen Rotalgengattung Sahlingia würdigte Kornmann (in Vorbereitung) die Verdienste seines Mitarbeiters um die Erforschung der Helgoländer Algenvegetation.

Schreiber bat mit Rücksicht auf seine Gesundheit - das Klima war ihm nicht zuträglich - um Versetzung auf das Festland. Auf der Suche nach einem Nachfolger wandte sich 1935 der Leiter der Biologischen Anstalt Helgoland, Arthur $\mathrm{Hag}$ m eie r (Direktor von 1934-1953; vgl. Bückmann, 1957), an seinen Bekannten Rudolf R i c h te r, den Direktor des Senckenberg-Museums in Frankfurt. Dieser hatte in Wilhelmshaven im Jahr 1928 mit Unterstützung der Reichsmarine ein Forschungsinstitut für marine Geologie eingerichtet. Durch Richters Vermittlung kam der Austausch Schreibers mit Peter Kornmann, einem Assistenten am Botanischen Institut der Universität Frankfurt am Main, zustande. 


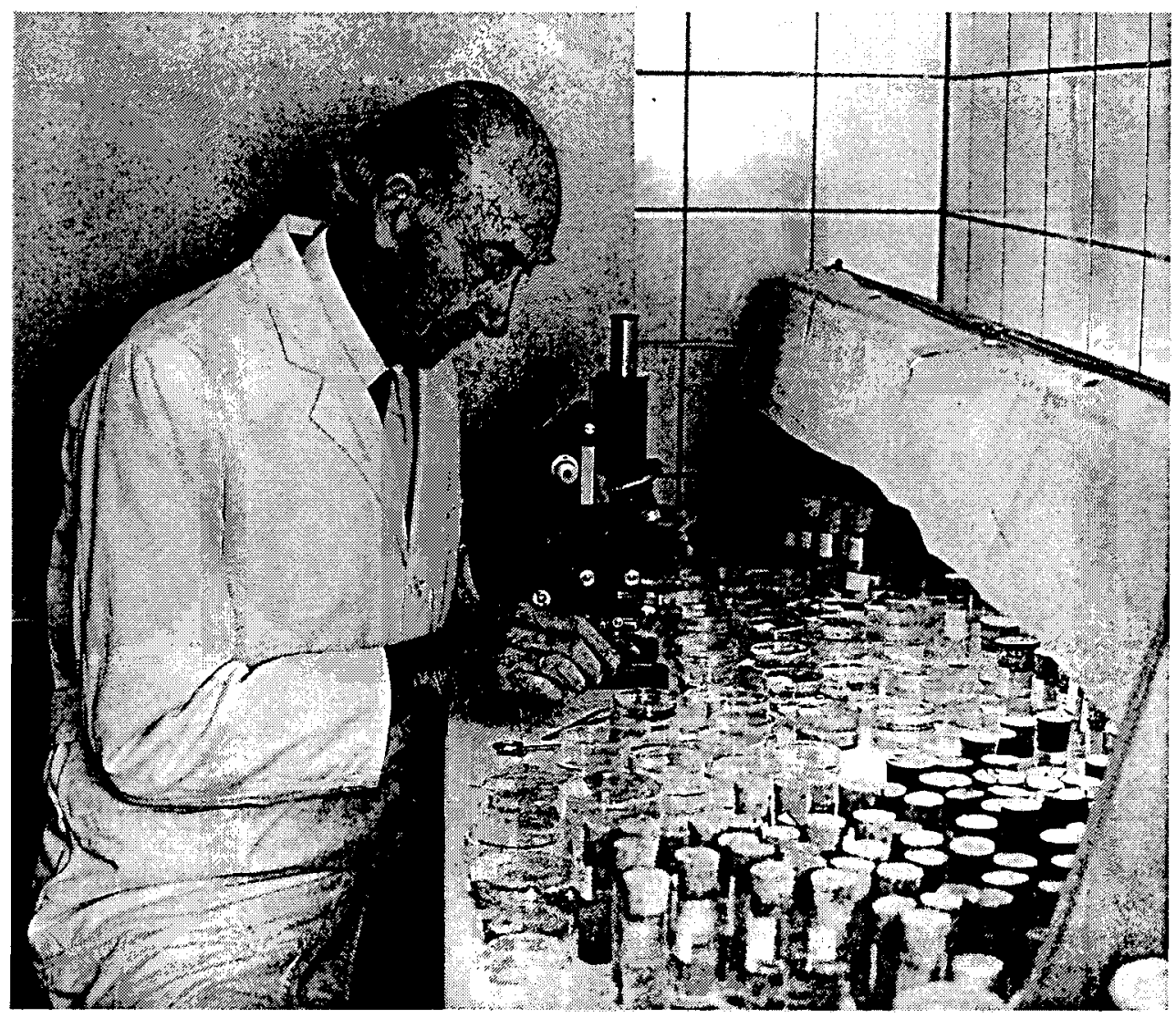

Abb. 14. Peter Kornmann, der vierte Kustos für Botanik und Leiter der Abteilung Meeresbotanik (Photo aus Privatbesitz)

\section{DER VIERTE KUSTOS: PETER KORNMANN}

Das Botanische Institut der Universität in Frankfurt am Main wurde damals von Friedrich Laibach (1885-1967) geleitet, einem Schüler von Strasburger. Laibachs Schüler und Assistent Peter Ko r n m a n n (Abb. 14, 15) hatte zunächst physiologisch an höheren Pflanzen gearbeitet (z. B. Kornmann, 1932; Laibach \& Kornmann, 1933). Nähere Bekanntschaft mit Meeresalgen machte er 1930 in Neapel, wo er Permeabilitätsstudien an der Grünalge Valonia durchführte (Kornmann, 1934). Weitere Forschungsaufenthalte an der Zoologischen Station in Neapel folgten 1933 und 1934. Kornmann übernahm am 1. 4. 1936 vertretungsweise Schreibers Stelle auf Helgoland. Für diesen wurde nach vorübergehender Tätigkeit am Botanischen Institut in Frankfurt eine persönliche Kustodenstelle am Institut für Pharmakognosie eingerichtet. Die nach einem Jahr vorgesehene Rückkehr nach Frankfurt schlug Kornmann zugunsten der ihm angebotenen Stelle als Kustos für Botanik an der Staatlichen Biologischen Anstalt Helgoland aus; die Stelle wurde ihm im Juli 1938 übertragen. 


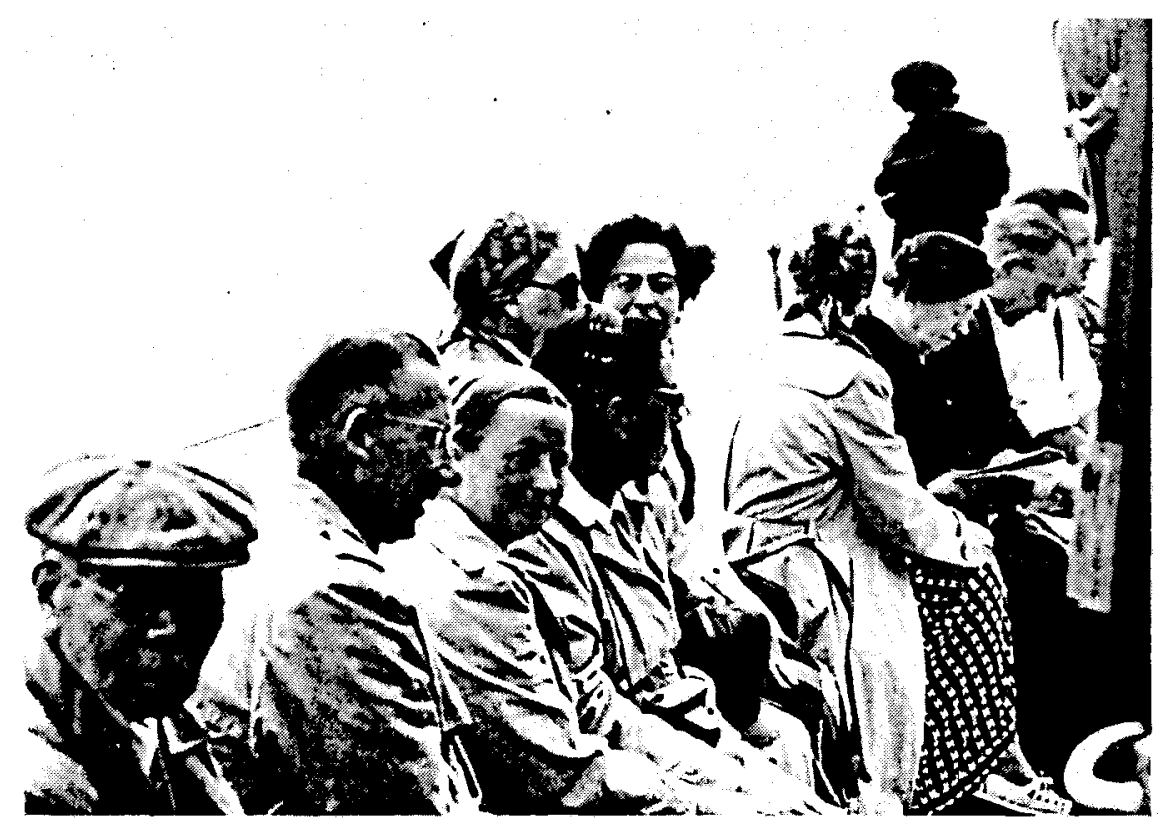

Abb. 15. Peter Kornmann und seine Frau Hilde Kornmann (2. und 3. v. li.) als Teilnehmer an einer Exkursion nach Roscoff, im Anschluß an den Internationalen Botanischen Kongreß in Paris, 1954. Weiter sind zu erkennen: Frau Hülsbruch (5. v. li.), Margaret Meyer aus Neuseeland (6. v. li.) sowie (beide lesend) Mary Parke aus Liverpool (8. v. li.) und Hans Adolf von Stosch aus Marburg (9. v. li.) (Photo aus Privatbesitz),

Inzwischen hatte Kornmann eine aufsehenerregende Entdeckung gemacht: er stellte den entwicklungsgeschichtlichen Zusammenhang zwischen den Grünalgen Halicystis und Derbesia fest; die morphologisch so unähnlichen Algen waren als Glieder eines heteromorphen Generationswechsels erkannt (Kornmann, 1938). Dieser Befund wurde von vielen Phykologen angezweifelt, bevor Feldmann (1950) die Richtigkeit an einem anderen Heteromorphenpaar dieser Gattungen bestätigte.

Die so erfolgreich begonnene Arbeit endete jäh mit dem Ausbruch des Zweiten Weltkrieges und der Einziehung zum Wehrdienst im August 1939. Der Marineartillerist auf Helgoland wurde 1941 zum Marinemeteorologen ausgebildet, war vorübergehend im Nordafrikafeldzug eingesetzt und wurde schließlich als Referent mit der Durchführung meteorologischer Forschungsarbeiten am Marineobservatorium in Greifswald betraut (z. B. Kornmann, 1943). Nach der Entlassung aus der Kriegsgefangenschaft im August 1945 fand sich die Familie - der Sohn Reimer Kornmann war 1939 auf Helgoland geboren worden - auf einem Gutshof in Hessen wieder. Helgoland war zerstört, der Gedanke, jemals dorthin zurückzukehren, schien absurd. Die Tätigkeit in einem Samenzuchtbetrieb in der Nähe von Kassel sicherte den Lebensunterhalt. Vor die Wahl gestellt, entschied Kornmann sich 1950 zur Rückkehr auf die inzwischen wieder eingerichtete Botanikerstelle im Zweiglaboratorium der Biologischen Anstalt in List/Sylt auf dem "Ellenbogen“.

Nach einer Unterbrechung von 11 Jahren konnte Kornmann seine Arbeiten ab Juni 


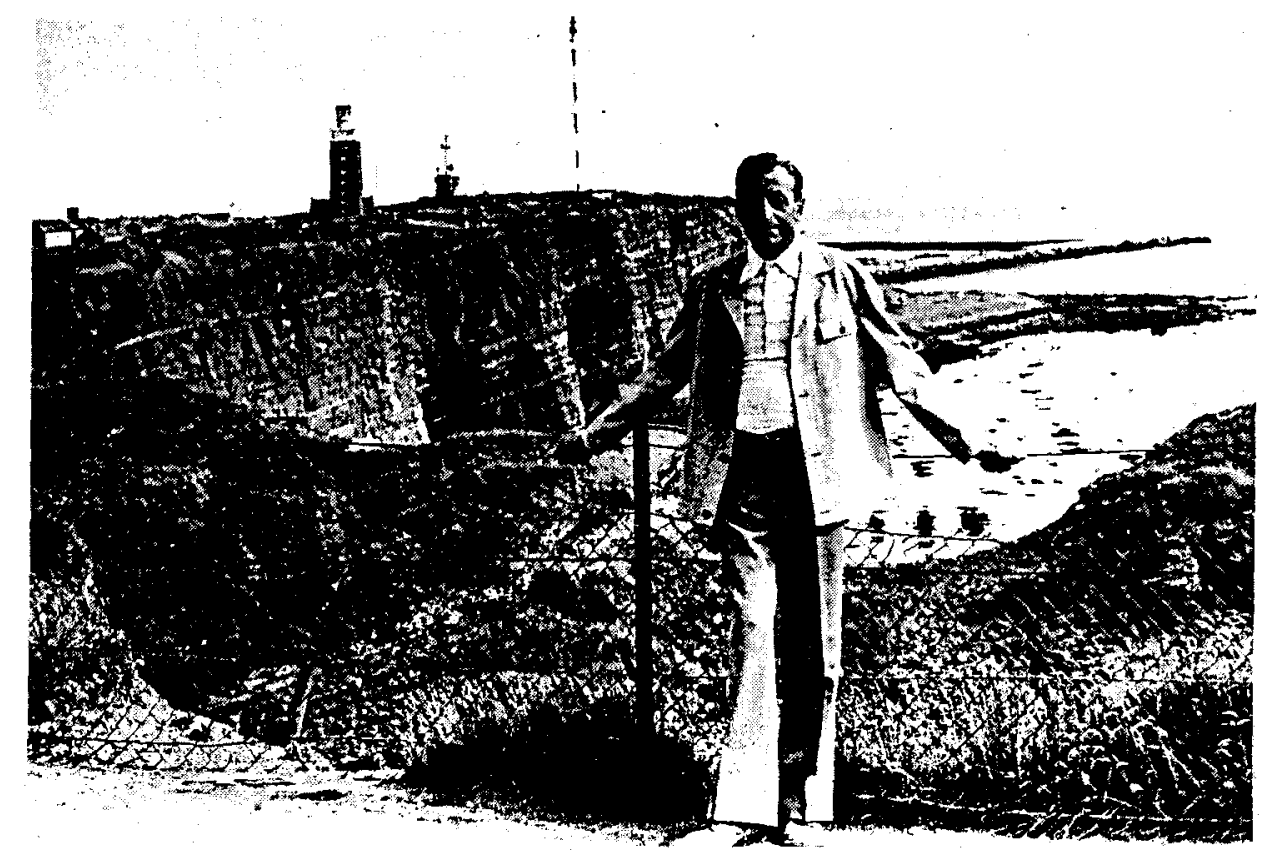

Abb. 16. Paul-Heinz Sahling, Technischer Assistent von Ernst Schreiber und Peter Kornmann (Photo aus Privatbesitz)

1950 in List fortsetzen. Die Wahl der Untersuchungsobjekte war in dem an Benthosalgen armen Areal (Kornmann, 1952) eine mehr zufälige. Beobachtungen an PhaeocystisKulturen (Kornmann, 1955) brachten neuen Erkenntnisse über die Struktur ihrer Schwärmer. Die Entwicklung von Acinetospora (Kornmann, 1953) und von Percursaria (Kornmann, 1956) wurde studiert. Die in Muschelschalen bohrende Grünalgengattung Gomontia, ursprünglich als fädige Alge mit auffallenden Sporangien angesehen, wurde als Konglomerat erkannt. Die Sporangien sind die Sporophyten im Lebenszyklus der scheibenförmigen Gomontia polyrhiza (Kornmann, 1959), der fädige Anteil wurde einer neuen Gattung Eugomontia zugeführt (Kornmann, 1960). Neben den experimentellen Arbeiten erschienen während der Jahre in List fünf Teile der aus dem Nachlaß von Paul Kuckuck geborgenen Ectocarpaceen-Studien; sie wurden später mit drei weiteren Teilen in einer Gesamtpublikation zusammengefaßt (Kuckuck, 1964).

Am 19. Juni 1959 wurde in Helgoland die Meeresstation der Biologischen Anstalt wiedereröffnet; Direktoren waren von 1953 bis 1960 Adolf B ü ckm a n n und von 1962 bis 1984 Otto Kinne. Im Mai 1959 war Peter Kornmann nach Helgoland versetzt worden. Das marine Milieu bot nun eine unerschöpfliche Fundgrube für die Bearbeitung zahlreicher lohnender Objekte.

In den folgenden Arbeiten wird das Kulturexperiment zur Basis der taxonomischen Revision der bei Helgoland vertretenen Arten zahlreicher Gattungen wie Urospora (Kornmann, 1961b), Porphyra (Kornmann, 1961c), Acrosiphonia (Kornmann, 1962b), Monostroma (Kornmann \& Sahling, 1962b), Ulothrix (Kornmann, 1964a), Chaetomorpha (Kornmann, 1972b), Blidingia (Kornmann \& Sahling, 1978), der Gattungen der Prasiolales 
(Kornmann \& Sahling, 1974) oder der Erythropeltidaceen (Kornmann \& Sahling, 1985). Damit ist nur ein Teil der zahlreichen Publikationen erwähnt (siehe Literaturverzeichnis). Das Interesse an der Aufklärung des Lebenszyklus steht hier überall im Vordergrund.

In wechselnder Vielfalt werden Grünalgen bearbeitet, aber auch Braunalgen, vom Nachweis der monözischen Gametophyten bei Desmarestia viridis (Kornmann, 1962c) bis zur taxonomischen Entwirrung des Botrytella (Sorocarpus)-Komplexes (Kornmann \& Sahling, 1988).

Bei zwei Arten der Rotalgengattung Erythrotrichia (Erythropeltidaceae) konnte der heteromorphe Generationswechsel einer mikroskopischen Scheiben- mit einer aufrechten Geschlechtsgeneration nachgewiesen werden. Die auf dieser Grundlage begründete Gattung Erythrotrichopeltis (Kornmann, 1984) wurde von Wynne (1986) der Gattung Porphyrostromium Trevisan 1848 zugeführt. Im Jahr 1882 hatte Berthold in Neapel den später vielfach angezweifelten - Befruchtungsvorgang bei Erythrotrichia obscura beobachtet. 105 Jahre danach konnte dieser Befund bestätigt und der entwicklungsgeschichtliche Zusammenhang mit einer Scheibengeneration im Kulturversuch festgestellt werden (Kornmann, 1987). Damit weisen die Erythropeltidales eine phylogenetische Parallele zu dem bekannten Generationenzyklus zwischen Conchocelis und Porphyra bei den Bangiales auf. Berthold (1882a) hatte bei seinen Untersuchungen der Bangiaceen im Golf von Neapel die Entdeckung des heteromorphen Generationswechsels bei Porphyrostromium knapp verfehlt.

Die taxonomischen Befunde gehen unmittelbar ein in die diversen Revisionen der "Check-lists of marine algae" für die Britischen Inseln (z. B. Parke \& Dixon, 1976), die ostkanadische Küste (z. B. South, 1984) oder den gesamten Nordatlantik (South \& Tittley, 1986). Seltenheiten der Helgoländer Algenflora werden erfaßt, vom Auftreten der Gametophyten von Bonnemaisonia hamifera bei Helgoland (Kornmann \& Sahling, 1962a) bis zum Fund der ostasiatischen Poryphyra yezoensis (Kornmann, 1986). Die kontinuierliche Beobachtung der Algenkulturen ermöglicht Untersuchungen zur Morphogenese verschiedener Grünalgen (Kornmann, 1965b, 1966, 1967). Die "Meeresalgen von Helgoland" (Kornmann \& Sahling, 1977) nebst Ergänzungen (Kornmann \& Sahling, 1983) fassen in umfangreicher photographischer Dokumentation das in Jahrzehnten erarbeitete Wissen zur Systematik und Entwicklungsgeschichte der Helgoländer marinen Makroalgen zusammen.

Der Nachweis von Codiolum im Lebenszyklus morphologisch unterschiedlicher Grünalgentaxa nimmt eine zentrale Position in Kornmanns Arbeiten ein (z. B. Kornmann, 1961a, 1961b, 1962a, 1972a) und führt zu phylogenetischen Folgerungen (Kornmann, 1963, 1965a, 1973), die im vorliegenden Band durch van den Hoek et al. (1988) näher dargestellt werden.

Am 9. Juni 1971 wird Peter Kornmann von der Universität Hamburg die Würde eines "Doktors der Naturwissenschaften ehrenhalber" (Dr. h. c.) verliehen. Die Pensionierung am 23. Oktober 1972, dem 65. Geburtstag, bedeutet keine Unterbrechung seiner wissenschaftlichen Arbeit. Durch die dankenswerte weitere Mitarbeit von Paul-Heinz Sahling ist die Biologische Anstalt Helgoland in der beneidenswert günstigen Lage, die entwicklungsgeschichtlich-systematische Tradition fortführen zu können. In der Nachfolge als Leiter der Abteilung Meeresbotanik erweitert Klaus L ün ing die Forschungsthematik auf die Ökophysiologie der Makroalgen. Lebenszyklen von Planktonalgen werden mit Schwerpunkt hinsichtlich der Diatomeen und parasitischer Protophyten durch Gerhard 
Dre bes untersucht, bezüglich der.Dinoflagellaten durch Malte Elbrä chter (Drebes, 1974; Drebes \& Elbrächter, 1976). Die Dynamik im Helgoländer Phytoplankton verfolgt Erik $\mathrm{Hagmeier}$, während die ionenphysiologischen Untersuchungen an Meeresalgen von Hanswerner Kess eler (bis zu seiner Pensionierung im Jahr 1987) eine bereits von Kormmann in Neapel begonnene Thematik aufgreifen (Kornmann, 1934; Kesseler, 1980).

\section{AUSBLICK}

Durch fast hundert Jahre wird nun die Entwicklung der marinen Algen Helgolands erforscht. Eine solche, mehrmals aus den Trümmern neu erstandene systematische und letztlich doch kontinuierliche Untersuchung einer Algenflora sucht ihresgleichen. Hans Adolf v on S t o S Ch (1908-1987), vorbildlich in seiner Geschicklichkeit im Experimentieren und Kultivieren wie in der Literaturkenntnis, formulierte einmal, daß gute Literaturkenntnis überflüssiges Experimentieren ersparen kann. Aber dazu gehört auch, daß man die Kompetenz der Verfasser des Schrifttums, auf das man sich bezieht, einzuschätzen weiß. "Unsere heutige biologische Wissenschaft breitet sich über den Literaturmassen der Vergangenheit aus, wie die modernen Städte antiken Ruhms über den Schuttlagen ihrer alten Kulturen, welche immer mächtiger und immer schwerer erreichbar anwachsen. Und ich möchte hier zeigen, daß es sich zu graben lohnt" (von Stosch, 1964: p. 140). Gerade beim naturhistorischen Arbeiten wird man immer von neuem auf den Generationenverbund verwiesen und im Bewußtsein gestärkt, daß jeder Untersucher und Autor als Glied in einer Kette von Vorgängern und Nachfolgern wirkt.

Danksagungen. Für zahlreiche Hinweise gebührt unser Dank den Herren Dr. Dr. Peter Kornmann, Paul-Heinz Sahling und Oberstudiendirektor a. D. Reimer Hans R'einhard Kuckuck, der uns freundlicherweise auch Photographien zur Veröffentlichung überließ. Weiter danken wir für Textergänzungen und Textkorrekturen den Herren Dr. Gerhard Drebes, Olaf Goemann, Tönnies Hornsmann, Prof. Dr. L. Kies, Dr. Bruno P. Kremer, Dr. Heye Rumohr, Frau Dipl.-Bibl. Ingrid Schritt und Herrn Prof. Dr. Heinz Schwenke.

\section{LITERATUR}

Berthold, G., 1882a. Die Bangiaceen des Golfes von Neapel und der angrenzenden MeeresAbschnitte. - Fauna Flora Golf. Neapel 8, 1-28.

Berthold, G., 1882b. Über die Verbreitung der Algen im Golf von Neapel nebst einem Verzeichnis der bisher beobachteten Arten. - Mitt. zool. Stn Neapel 3, 393-536.

Bold, H., 1942. The cultivation of algae. - Bot. Rev. 8, 69-138.

Braun, A., 1855. Algarum unicellularium genera nova et minus cognita. Engelmann, Leipzig, $111 \mathrm{pp.}$

Bückmann, A., 1957. Arthur Hagmeier. - Ber. dt. wiss. Kommn Meeresforsch. 15, 70-76.

Bückmann, A., 1959. Die Wiedereröffnung der Biologischen Anstalt Helgoland auf der Insel Helgoland 1959. - Helgoländer wiss. Meeresunters. 7, 1-50.

Chun, C., 1903. Aus den Tiefen des Weltmeeres. Fischer, Jena, 592 pp.

Cohn, F., 1862. Ueber die Vegetation des Landes und des Meeres von Helgoland. - Jber. Abh. schles. Ges. vaterl. Kultur Breslau 39, 89-91.

Cohn, F. 1865. Über einige Algen von Helgoland. In: Beiträge zur Kenntnis und Verbreitung der Algen. Hrsg. von L. Rabenhorst. Leipzig, 2, 17-40.

Cohn, P., 1901. Ferdinand Cohn. Blätter der Erinnerung. Kern, Breslau, 266 pp.

Denkschrift betreffend die Errichtung einer biologischen Anstalt auf Helgoland, 1892. Sammlung sämtlicher Drucksachen des Hauses der Abgeordneten aus der 17. Legislaturperiode. 4. Session. 32. Sitzung vom 15. 3. 1892. 
Depdolla, P., 1920. Das meeresbiologische Praktikum auf Helgoland. - Aus der Natur 1920, 70-74.

Drebes, G., 1974. Marines Phytoplankton. Thieme, Stuttgart, 186 pp.

Drebes, G. \& Elbrächter, M., 1976. A checklist of planktonic diatoms and dinoflagellates from Helgoland and List (Sylt), German Bight. - Botanica mar. 19, 75-83.

Ehrenbaum, E., 1910. Das Aquarium der Biologischen Anstalt auf Helgoland. - Int. Revue ges. Hydrobiol. Hydrogr. 3, 418-446.

Ehrenbaum, E., 1923. Friedrich Heincke zu seinem 70. Geburtstage. - Wiss. Meeresunters. (Abt. Helgoland) 15 (1), 1-11.

Ehrenberg, C. G., 1834-1835. Das Leuchten des Meeres. Neue Beobachtungen nebst Übersicht der Hauptmomente der geschichtlichen Entwicklung dieses merkwürdigen Phänomens. - Abh. dt. Akad. Wiss., Berlin (Klasse für Math., Physik und Techn.) 1834, 411-575.

Falkenberg, P., 1878. Die Meeres-Algen des Golfes von Neapel. - Mitt. zool. Stn Neapel 1, $218-277$.

Falkenberg, P., 1879. Die Befruchtung und der Generationswechsel von Cutleria. - Mittl. zool. Stn Neapel 1,420-447.

Feldmann, J., 1950. Sur l'existence d'une alternance de générations entre l'Halicystis parvula Schmitz et le Derbesia tenuissima (De Not.) Crouan. - C. r. hebd. Séanc. Acad. Sci. Paris 230, $322-323$.

Festschrift der Preussischen Kommission zur wissenschaftlichen Untersuchung der deutschen Meere zu Kiel aus Anlaß ihres 50jährigen Bestehens, 1921. Lipsius \& Tischer, Kiel, 194 pp.

Föyn, B., 1934. Lebenszyklus der Chlorophycee Cladophora suhriana Kützing. - Arch. Protistenk. $83,1-56$.

Francé, R. H., 1908. Das Leben der Pflanze. II. Abteilung: Floristische Lebensbilder. Franckh, Stuttgart, 1, 1-564.

Funk, G., 1927. Die Algenvegetation des Golfs von Neapel. Nach neueren ökologischen Untersuchungen. - Pubbl. Staz. zool. Napoli 7 (Suppl.), 1-507.

Funk, G., 1955. Beiträge zur Kenntnis der Meeresalgen von Neapel. Zugleich mikrophotographischer Atlas. - Pubbl. Staz. zool. Napoli 25 (Suppl.), 1-178.

Gessner, F, 1931. Die biologische Forschungsstation auf Hiddensee. - Arch. Hydrobiol. 23, 161-164.

Gessner, F., 1940. Meer und Strand. Quelle \& Meyer, Leipzig, 278 pp.

Gessner, F., 1955. Hydrobotanik. I. Energiehaushalt. VEB De,utscher Verl. Wiss., Berlin, 517 pp.

Gessner, F., 1957. Meer und Strand. 2. Aufl. VEB Deutscher Verl. Wiss,, Berlin, 426 pp.

Gessner, F., 1959. Hydrobotanik. II. Stoffhaushalt. VEB Deutscher Verl. Wiss., Berlin, 701 pp.

Gustavs, A., 1962. Gerhart Hauptmann und Hiddensee. Petermänken, Schwerin, 227 pp.

Hagmeier, A., 1925. Neue Aquariumseinrichtungen der Staatlichen Biologischen Anstalt auf Helgoland. - Int. Revue ges. Hydrobiol. Hydrogr. 12, 405-416.

Hagmeier, A., 1934. Aufgaben und Bedeutung der Preußischen Biologischen Anstalt auf Helgoland. - Der Biologe. 3 (7), 161-165.

Hagmeier, A., 1952. Helgoland und die Biologische Anstalt. In: Helgoland ruft. Hrsg. von J. Packroß \& P. Rickmers. Schultheis, Hamburg, 115-123.

Hallier, E., 1863a. Nordseestudien. Meißner, Hamburg, 336 pp.

Hallier, E., 1863b. Die Vegetation auf Helgoland. Meißner, Hamburg, 56 pp.

Heering, W., 1901. Leben und Werke des Algologen J. N. von Suhr. - Schr. naturw. Ver. Schlesw.Holst. 12, 241-250.

Heering, W., 1906. Die Süßwasseralgen Schleswig-Holsteins. - Jb. hamb. wiss. Anst. 23 (3. Beih.), 59-150.

Heincke, F., 1894. Die Arbeiten der Biologischen Anstalt Helgoland im Jahre 1893. - Wiss. Meeresunters. (Abt. Helgoland) 1, 1-33.

Heincke, F., 1910. Botanische Gärten und Institute. Die Biologische Anstalt auf Helgoland. - Bot. Zbl. 18-19, 139-142.

Heincke, F., 1918. Die Biologische Anstalt auf Helgoland 1892-1917. - Naturwissenschaften 6, $569-572$.

Henking, H., 1899. Die Königliche Biologische Anstalt auf Helgoland und ihre Thätigkeit. - Mitt. dt. SeefischVer, 15, 107-118.

Hensen, V., 1887. Über die Bestimmung des Planktons oder des im Meere treibenden Materials an Pflanzen und Thieren. - Ber. Kommn wiss. Unters. dt. Meere, Kiel, 5, 1-107. 
Herter, K., 1979. Begegnungen mit Menschen und Tieren. Erinnerungen eines Zoologen. Duncker \& Humblot, Berlin, 598 pp.

Heuss, T., 1940. Anton Dohrn in Neapel. Atlantis, Berlin, 319 pp.

Hoek C. van den, Stam, W. T. \& Olsen, J. L., 1988. The emergence of a new chlorophytan system, and Dr. Kornmann's contribution thereto. - Helgoländer Meeresunters. 42, 339-383.

Hoffmann, C., 1934. Wilhelm Nienburg. - Ber. dt. bot. Ges. 51, 231-245.

Hübel, H., 1982. Fünf Jahrzehnte produktionsbiologischer Untersuchungen in den Brackgewässern Rügens und des Darss. - Wiss. Z. Emst-Moritz-Arndt-Univ.Greifswald (Math.-Nat. Reihe) 31 , 3-9.

Kies, L., 1987. Phykologie in Hamburg. - Ber. dt. bot. Ges. 100, 233-250.

Kinne, O., 1980. Die Biologische Anstalt Helgoland. In: Helgoland. Hrsg. von H. P. Rickmers. Dingwort, Hamburg, 75-86.

Kjellman, F. R., 1878. Über Algenregionen und Algenformationen im östlichen Skager Rack. - Bih. K. svenska Vetensk Akad. Handl. 5 (6), 1-35.

Kjellman, F. R., 1883. The algae of the Arctic Sea. Kgl. Boktryckeriet, Stockholm, 350 pp.

Kesseler, H., 1980. On the selective adsorption of cations in the cell wall of Valonia utricularis. Helgoländer Meeresunters. 34, 151-158.

Kornmann, P., 1932. Der Einfluß von Kondensatorentladungen auf das Wachstum von Keimpflanzen. - Jb. wiss. Bot. 76, 283-310.

Kornmann, P., 1934. Osmometer aus lebenden Valonia-Zellen und ihre Verwendbarkeit zu Permeabilitätsuntersuchungen. - Planta 21, 340-350.

Kornmann, P., 1938. Zur Entwicklungsgeschichte von Derbesia und Halicystis. - Planta 28, 464-470.

Kornmann, P., 1943. Der Einfluß der meteorologischen Bedingungen auf Erscheinungsform und Dichte des künstlichen Nebels. - Erfahr.-Ber. Marinewetterdienst. 6 (4):

Kormmann, P., 1952. Die Algenvegetation von List auf Sylt. - Helgoländer wiss. Meeresunters. 4, 55-61.

Kornmann, P., 1953. Der Formenkreis von Acinetospora crinita (Carm.). - Helgoländer wiss. Meeresunters, 4, 205-224.

Kornmann, P., 1955. Beobachtungen an Phaeocystis-Kulturen. - Helgoländer wiss. Meeresunters, 5 , 218-233.

Kornmann, P., 1956. Zur Morphologie und Entwicklung von Percursaria percursa. - Helgoländer wiss. Meeresunters. 5, 259-272.

Kornmann, P., 1959. Die heterogene Gattung Gomontia. I. Der sporangiale Anteil, Codiolum polyrhizum. - Helgoländer wiss. Meeresunters. 6, 229-238.

Kornmann, P., 1960. Die heterogene Gattung Gomontia. II. Der fädige Anteil, Eugomontia sacculata. - Helgoländer wiss. Meeresunters. 7, 59-71.

Kornmann, P., 1961a, Über Spongomorpha lanosa und ihre Sporophytenformen. - Helgoländer wiss. Meeresunters. 7, 195-205.

Kornmann, P., 1961b. Über Codiolum und Urospora. - Helgoländer wiss. Meeresunters. 8, 42-57.

Kornmann, P., 1961c. Zur Kenntnis der Porphyra-Arten von Helgoland. - Helgoländer wiss. Meeresunters. $8,176-192$.

Kornmann, P., 1962a. Die Entwicklung von Monostroma grevillei. - Helgoländer wiss. Meeresunters. $8,195-202$.

Kornmann, P., 1962b. Eine Revision der Gattung Acrosiphonia. - Helgoländer wiss. Meeresunters. 8, $219-242$.

Kornmann, P., 1962c. Der Lebenszyklus von Desmarestia viridis. - Helgoländer wiss. Meeresunters. 8, 287-292.

Kornmann, P., 1963. Die Ulotrichales, neu geordnet auf der Grundlage entwicklungsgeschichtlicher Befunde. - Phycologia 3, 60-68.

Kornmann, P., 1964a. Die Ulothrix-Arten von Helgoland. I. - Helgoländer wiss. Meeresunters. 11, $27-38$.

Kornmann, P., 1964b. Zur Biologie von Spongomorpha aeruginosa (Linnaeus) van den Hoek. Helgoländer wiss. Meeresunters. 11, 200-208.

Kornmann, P., 1965a. Ontogenie und Lebenszyklus der Ulotrichales in phylogenetischer Sicht. Phycologia 3, 60-68. 
Kornmann, P., 1965b. Zur Analyse des Wachstums und des Aufbaus von Acrosiphonia. - Helgoländer wiss. Meeresunters. 12, 219-238.

Kornmann, P., 1966. Wachstum und Zellteilung bei Urospora. - Helgoländer wiss. Meeresunters. 13, $73-83$.

Kornmann, P., 1967. Wachstum und Aufbau von Spongomorpha aeruginosa (Chlorophyta, Acrosiphoniales). - Blumea 15, 9-16.

Kornmann, P., 1972a. Les sporophytes vivant en endophyte de quelques Acrosiphoniacées et leurs rapports biologiques et taxonomiques. - Mém. Soc. bot. Fr. 1972, 75-86.

Kornmann, P., 1972b. Ein Beitrag zur Taxonomie der Gattung Chaetomorpha (Cladophorales, Chlorophyta). - Helgoländer wiss. Meeresunters. 23, 1-31.

Kornmann, P., 1973. Codiolophyceae, a new class of Chlorophyta. - Helgoländer wiss. Meeresunters. $25,1-13$.

Kornmann, P., 1984 Erythrotrichopeltis, eine neue Gattung der Erythropeltidaceae (Rhodophyceae Bangiophycidae). - Helgoländer Meeresunters. 38, 207-224.

Kornmann, P., 1986. Porpyhra yezoensis bei Helgoland - eine entwicklungsgeschichtliche Studie. Helgoländer Meeresunters. 40, 327-342.

Kornmann, P., 1987. Der Lebenszyklus von Porphyrostromium obscurum (Bangiophyceae, Rhodophyta). - Helgoländer Meeresunters. 41, 127-137.

Kormmann, P. \& Sahling, P.-H., 1962a. Geschlechtspflanzen von Bonnemaisonia hamifera Hariot bei Helgoland. - Helgoländer wiss. Meeresunters. 8, 298-301.

Kormmann, P. \& Sahling, P.-H., 1962b. Zur Taxonomie und Entwicklung der Monostroma-Arten von Helgoland. - Helgoländer wiss. Meeresunters. 8, 302-230.

Kornmann, P. \& Sahling, P.-H., 1974. Prasiolales (Chlorophyta) von Helgoland. - Helgoländer wiss. Meeresunters. 26, 99-133.

Kornmann, P. \& Sahling, P.-H., 1977. Meeresalgen von Helgoland. - Helgoländer wiss. Meeresunters. $29,1-289$.

Kormmann, P. \& Sahling, P.-H., 1978. Die Blidingia-Arten von Helgoland. - Helgoländer wiss. Meeresunters. 31, 391-413.

Kornmann, P. \& Sahling, P.-H., 1980. Kalkbohrende Mikrothalli bei Helminthocladia und Scinaia. Helgoländer Meeresunters. 34, 31-40.

Kornmann, P. \& Sahling, P.-H., 1983. Meeresalgen von Helgoland: Ergänzung. - Helgoländer Meeresunters. 36, 1-65.

Kornmann, P. \& Sahling, P.-H., 1985. Erythropeltidaceen (Bangiophyceae, Rhodophyta) von Helgoland. - Helgoländer Meeresunters. 39, 213-236 (1985).

Kornmann, P. \& Sahling, P.-H., 1988. Die Entwirrung des Botrytella (Sorocarpus)-Komplexes (Ectocarpaceae, Phaeophyta). - Helgoländer Meeresunters. 42, 1-12.

Kuckuck, P., 1894. Bemerkungen zur marinen Algenvegetation Helgolands. - Wiss. Meeresunters. (Abt. Helgoland) 1, 225-263.

Kuckuck, P., 1897a. Beiträge zur Kenntnis der Meeresalgen. 1. Über Rhododermis parasitica Batters. - 2. Über Rhodochorton membranaceum Magnus, eine chitinbewohnende Alge. - 3. Die Gattung Mikrosyphar Kuckuck. - 4. Über zwei höhlenbewohnende Phaeosporeen. - Wiss. Meeresunters. (Abt. Helgoland) 2, 329-370.

Kuckuck, P., 1897b. Bemerkungen zur marinen Algenvegetation Helgolands. II. - Wiss. Meeresunters. (Abt. Helgoland) 2, 373-400.

Kuckuck, P., 1897c. Über marine Vegetationsbilder. - Ber. dt. bot. Ges. 15, 441-447.

Kuckuck, P., 1899. Beiträge zur Kenntnis der Meeresalgen. 5. Ein neuer Asperococcus mit beiderlei Sporangien. 6. Die Gattung Myriotrichia Harvey. 7. Über den Ectocarpus investiens der Autoren. 8. Compsonema, ein neues Genus der Phaeosporeen. 9. Über den Generationswechsel von Cutleria multifida. - Wiss. Meeresunters. (Abt. Helgoland) 3, 13-82.

Kuckuck, P., 1900. Über Algenkulturen im freien Meere. - Wiss. Meeresunters. (Abt. Helgoland) 4, 83-90.

Kuckuck, P., 1905. Der Strandwanderer. Lehmanns, München, 76 pp.

Kuckuck, P., 1908. Der Nordseelotse. Meißner, Hamburg, 239 pp.

Kuckuck. P., 1910. Über die Eingewöhnung von Pflanzen wärmerer Zonen auf Helgoland. - Bot. Z. $68,49-86$.

Kuckuck, P., 1912. Beiträge zur Kenntnis der Meeresalgen. 10. Neue Untersuchungen über Nemo- 
derma Schousboe. 11. Die Fortpflanzung der Phaeosporeen. 12. Über Platoma Bairdii (Farl.) Kck. - Wiss. Meeresunters. (Abt. Helgoland) 5, 189-210.

Kuckuck, P., 1917. Über Zwerggenerationen bei Pogotrichum und über die Fortpflanzung von Laminaria, - Ber. dt. bot. Ges. 35, 557-578.

Kuckuck, P., 1929. Fragmente einer Monographie der Phaeosporeen. Nach dem Tode des Verfassers hrsg. von Wilhelm Nienburg. - Wiss. Meeresunters. (Abt. Helgoland) 17 (2), 1-93.

Kuckuck, P., 1964. Ectocarpaceen-Studien. Hrsg. von Peter Kornmann. Biologische Anstalt Helgoland, Hamburg, $239 \mathrm{pp}$.

Küster, E., 1953. Erinnerungen eines Botanikers. Nach dem Manuskript herausgegeben von Gertrud Küster-Winkelmann. Brühl, Gießen, 456 pp.

Kützing. F. T., 1844. Die kieselschaligen Bacillarien oder Diatomeen. Köhne, Nordhausen, $152 \mathrm{pp}$. (Reprint, Koeltz 1983).

Kützing, F. T., 1845. Phycologia germanica, d. i. Deutschlands Algen in bündigen Beschreibungen. Köhne, Nordhausen, $340 \mathrm{pp}$.

Kützing, F. T., 1960. Aufzeichnungen und Erinnerungen. Hrsg. von R. H. W. Müller \& R. Zaunick. Barth, Leipzig, $300 \mathrm{pp}$.

Laibach, F. \& Kornmann, P., 1933. Zur Frage des Wuchsstofftransportes in der Haferkoleoptile. Planta 21, 396-418.

Leick, E., 1930. Die Biologische Forschungsstation Hiddensee. Abel, Greifswald, 19 pp.

Levring, T., 1959. In Memoriam Curt Hoffmann. - Botanica mar. 1, 65-66.

Lindemann, E., 1889. Die Nordseeinsel Helgoland in topographischer, geschichtlicher, sanitärer Beziehung. Hirschwald, Berlin, 116 pp.

Lorenz, J. R., 1863. Physicalische Verhältnisse und Vertheilung der Organismen im Quarnerischen Golfe. Wien, $379 \mathrm{pp}$.

Lüning, K., 1970. Tauchuntersuchungen zur Vertikalverbreitung der sublitoralen Helgoländer Algenvegetation. - Helgoländer wiss. Meeresunters. 21, 271-291.

Lüning, K., 1985. Meeresbotanik. Thieme, Stuttgart, 375 pp.

Meyer-Waarden, P. F., 1970. Aus der deutschen Fischerei. Heenemann, Berlin, 359 pp.

Mielck, W., 1919. Ueber das Schicksal der Helgoländer Biologischen Anstalt im Kriege und die Wiederaufnahme ihrer Tätigkeit nach Friedensschluß. - Fischerbote 11, 184-188.

Mielck, W., 1930. Die Preussische Biologische Anstalt auf Helgoland. In: Forschungsinstitute, ihre Geschichte, Organisation und Ziele. Hrsg. von L. Brauer. Hartung, Hamburg, 175-199.

Möbius, K., 1877. Die Auster und die Austernwirthschaft. Wiegandt, Hempel \& Parey, Berlin, 126 pp.

Möbius, M., 1937. Geschichte der Botanik. Fischer, Jena, 458 pp.

Mohrhenn, W., 1928. Helgoland zur Zeit der Kontinentalsperre. Ebering, Berlin, 87 pp.

Müller, G. H. \& Groeben, C., 1984. Die Zoologische Station in Neapel - von ihren Anfängen bis heute - ein "permanenter Kongreß". - Naturw. Rdsch., Stuttg. 37, 429-437.

Müller, I., 1976. Die Geschichte der Zoologischen Station in Neapel von der Gründung durch Anton Dohrn bis zum Ersten Weltkrieg und ihre Bedeutung für die Entwicklung der modernen biologischen Wissenschaften. Habil.-Schr., Univ. Düsseldorf, 301 pp.

Nienburg, W., 1908. Zur Keimungs- und Wachstumsgeschichte der Delesseriaceen. - Bot. Ztg 66, 183-209.

Nienburg, W., 1910. Die Oogonentwicklung bei Cystoseira und Sargassum. - Flora, Jena 101, $167-180$.

Nienburg, W., 1913. Die Konzeptakelentwicklung bei Fucaceen. - Z. Bot. 5, 1-27.

Nienburg, W., 1925. Die Besiedelung des Felsstrandes und der Klippen von Helgoland, Teil II. Die Algen. - Wiss. Meeresunters, (Abt. Helgoland) 15 (19), 1-15.

Nienburg, W., 1927. Studien zur Ökologie der Wattflora. I. Der Königshafen bei List auf Sylt. - Wiss. Meeresunters. (Abt. Kiel) 20, 146-196.

Nienburg, W., 1930. Die festsitzenden Pflanzen der nordeuropäischen Meere. In: Handbuch der Seefischerei Nordeuropas. Hrsg. von H. Lübbert, E. Ehrenbaum \& A. Wilter. Schweizerbart, Stuttgart, 1(4), 1-51.

Nienburg, W., 1933. Johannes Reinke. Nachruf. - Wiss. Meeresunters. (Abt. Kiel) 21, VII-XIV.

Nienburg, W. \& Hoffmann, C., 1936. Meeresalgen. In: Das botanische Schrifttum von SchleswigHolstein, Hamburg und Lübeck. Hrsg. von W. Christiansen \& W. Christiansen. Heimat und Erbe, Kiel, 153-177. 
Nienburg, W. \& Kolumbe, E., 1931. Studien zur Ökologie der Wattflora. II. Das Neufelder Watt im Elbmündungsgebiet. - Wiss. Meeresunters. (Abt. Kiel) 21, 72-114.

Ohle, W., 1974. Fritz Gessner. - Arch. Hydrobiol. 74, 276-286.

Oltmanns, F., 1922-1923. Morphologie und Biologie der Algen. Fischer, Jena, 1-3, 459 pp., 439 pp., $558 \mathrm{pp}$.

Overbeck, F., 1968. Botanik. In: Geschichte der Mathematik, der Naturwissenschaften und der Landwirtschaftswissenschaften. Hrsg, von K. Jordan, Wachholtz, Neumünster, 127-160.

Packroß, J., 1952. Vom Schmugglernest zum Nordseebad. In: Helgoland ruft. Hrsg. von J. Packroß \& P. Rickmers. Schultheis, Hamburg, 71-79.

Parke, M. \& Dixon, P. S., 1976. Check-list of British marine algae - third revision. - J. mar. biol. Ass. U. K. $56,527-594$.

Peter, A., 1910. Über den Stand der Algenforschung in Niedersachsen. - Jber. niedersächs. bot. Ver. $1-2,1-6$.

Pilger, R., 1919. Paul Kuckuck. - Ber. dt. bot. Ges. 36, 63-70.

Pirson, A., 1972. Ernst Georg Pringsheim 1881-1970. - Ber. dt. bot. Ges. 85, 651-659.

Pringsheim, E. G., 1954. Algenreinkulturen, ihre Herstellung und Erhaltung. Fischer, Jena, $109 \mathrm{pp}$.

Pringsheim, N., 1855. Über die Befruchtung der Algen. - Mber. Akad. Wiss. Berlin 1855, 133-165.

Pringsheim, N., 1862. Beiträge zur Morphologie der Meeres-Algen. - Abh. dt. Acad. Wiss., Berlin (Klasse für Math., Physik und Techn.) 1862, 1-37.

Pringsheim, N., 1873. Ueber den Gang der morphologischen Differenzierung in der SphacelarienReihe. - Abh. dt. Acad. Wiss., Berlin (Klasse für Math., Physik und Techn.) 1873, 137-191.

Provasoli, L., Mclaughlin, J. J. A. \& Droop, M. R., 1957. The development of artificial media for marine algae. - Arch. Mikrobiol. 25, 392-428.

Reinke, J., 1878a. Entwicklungsgeschichtliche Untersuchungen über die Dictyotaceen des Golfs von Neapel. - Nova Acta Acad. Caesar. Leop. Carol. 40, 1-56.

Reinke. J., 1878 b. Entwicklungsgeschichtliche Untersuchungen über die Cutleriaceen des Golfs von Neapel. - Nova Acta Acad. Caesar. Leop. Carol. 40, 57-96.

Reinke. J., 1888. Die braunen Algen (Fucaceen und Phaeosporeen) der Kieler Bucht. - Ber. dt. bot. Ges. 6, 14-20.

Reinke. J., 1889a. Algenflora der Westlichen Ostsee deutschen Antheils. Eine systematisch-pflanzengeographische Studie. - Ber. Kommn wiss. Unters. dt. Meere, Kiel, 6, 1-101.

Reinke, J., 1889b. Atlas deutscher Meeresalgen. Parey, Berlin, 1, 1-34.

Reinke. J., 1889c. Notiz über die Vegetationverhältnisse in der deutschen Bucht der Nordsee. - Ber. dt. bot. Ges. 7, 367-369.

Reinke. J., 1890. Das botanische Institut und die botanische Meeresstation in Kiel. - Bot. Zbl. 1890, $6-8,37-42$.

Reinke, J., 1891. Die braunen und rothen Algen von Helgoland. - Ber. dt. bot. Ges. 9, 271-273.

Reinke. J., 1892. Atlas deutscher Meeresalgen. Parey, Berlin, 2, 35-70.

Reinke, J., 1925. Mein Tagewerk. Herder, Freiburg, 495 pp.

Remane, A., 1968. Zoologie und Meereskunde. In: Geschichte der Mathematik, der Naturwissenschaften und der Landwirtschaftswissenschaften. Hrsg. von K. Jordan. Wachholtz, Neumünster, 161-179.

Sachtleben, R., 1967. Justus von Liebig und Friedrich Wöhler. In: Der Natur die Zunge lösen - Leben und Leistung großer Forscher. Hrsg. von W. Gerlach. Ehrenwirth, München, 350 pp.

Sachse, A., 1928. Friedrich Althoff und sein Werk. Mittler, Berlin, $361 \mathrm{pp}$.

Samhaber, E., 1951. Helgoland - Schicksal und Symbolik. - Merian 4 (1), 3-6.

Sauvageau, C., 1915. Sur la sexualité hétérogamique d'une Laminaire (Saccorhiza bulbosa). - C. r. hebd. Séanc. Acad. Sci., Paris 161, 796-799.

Schleiden. M. J., 1867. Das Meer. Sacco, Berlin, 710 pp.

Schmeil, O., 1893. Die zoologische Station zu Rovigno. - Zool. Anz. 16, 401-404.

Schmidt, O. C., 1928. Die Algenvegetation Helgolands. In: Vegetationsbilder. Hrsg, von G. Karsten. Fischer, Jena, 19(5), Taf. 25-30.

Schmidt, O. C., 1935. Neue oder bemerkenswerte Meeresalgen aus Helgoland I. - Hedwigia 75 , $150-158$.

Schmidt, O. C., 1938. Zwei neue Grünalgen aus Helgoland. - Hedwigia 77, 231-232.

Schreiber, E., 1927. Die Reinkultur von marinem Phytoplankton und deren Bedeutung für die 
Erforschung der Produktionsfähigkeit des Meerwassers. - Wiss. Meeresunters. (Abt. Helgoland) $16,1-34$.

Schreiber, E., 1930. Untersuchungen über Parthenogenesis, Geschlechtsbestimmung und Bastardisierungsvermögen bei Laminarien. - Planta 12, 331-353.

Schreiber, E., 1932. Über die Entwicklungsgeschichte und die systematische Stellung der Desmarestiaceen. - Z. Bot. 25, 561-582.

Schreiber, E., 1935. Über Kultur und Geschlechtsbestimmung von Dictyota dichotoma. - Planta 24, 266-275.

Schwenke, H., 1964. Vegetation und Vegetationsbedingungen in der westlichen Ostsee (Kieler Bucht). - Kieler Meeresforsch. 20, 155-168.

Schwenke, H., 1969. Meeresbotanische Untersuchungen in der westlichen Ostsee als Beitrag zu einer marinen Vegetationskunde. - Int. Rev. ges. Hydrobiol. 54, 35-94.

Schwenke, H., 1974. Die Benthosvegetation. In: Meereskunde der Ostsee. Hrsg. von L. Magaard \& G. Rheinheimer. Springer, Berlin, 131-146.

South, G. R., 1984., A check-list of marine algae of eastern Canada - second revision. - Can. J. Bot. $62,680-704$.

South, G. R. \& Tittley, I., 1986. A checklist and distributional index of the benthic marine algae of the North Atlantic Ocean. Huntsman Marine Laboratory \& British Museum (Natural History), St. Andrews \& London, $76 \mathrm{pp}$.

Steubing, L., 1958. Erich Leick. 1882-1956. - Ber. dt. bot. Ges. 70, (51)-(53).

Stosch, H. A. von, 1962. Kulturexperiment und Ökologie bei Algen. - Kieler Meeresforsch. 18 (Sonderh.), 13-27.

Stosch, H. A. von, 1964. Zum Problem der sexuellen Fortpflanzung in der Peridineengattung Ceratium. - Helgoländer wiss. Meeresunters. 10, 140-152.

Strasburger, E., 1884. Das botanische Praktikum. Fischer, Jena, 664 pp.

Thorson, G., 1972. Erforschung des Meeres. Eine Bestandsaufnahme. Kindler, München, 253 pp.

Vauk, G. (Hrsg.), 1977. Geschichte der Vogelwarte und der Vogelforschung auf der Insel Helgoland. Niederelbe-Druck, Otterndorf, $159 \mathrm{pp}$.

Wohlenberg, E., 1953. Helgoland als Stätte der Meeresforschung. - Veröff. Schlesw.-Holst. Univ.Ges. 5, 58-90.

Wollny, R., 1881. Die Meeresalgen von Helgoland. - Hedwigia 20 (1-2), 1-32.

Wollny, R, 1886. Algologische Mitteilungen. 5. Meeresalgen von Helgoland. - Hedwigia 25, 132.

Wynne, M. J., 1986. Porphyrostromium Trevisan (1849) vs. Erythrotrichopeltis Kornmann (1984) (Rhodophyta). - Taxon 35, 328-329.

Zavodnik, D., 1983. 400 years of the Adriatic marine science. - Thalassia jugosl. 19, 405-429.

Zimmermann, W., 1923. Neue einzellige Helgoländer Meeresalgen. Zugleich ein Beitrag zur Polaritätsfrage der Algen. - Ber. dt. bot. Ges. 41, 285-292.

Zimmermann, W. 1924. Helgoländer Meeresalgen. I - VI. - Wiss. Meeresunters. (Abt. Helgoland) $16,1-25$ 